\title{
Thermal comfort in winter incorporating solar radiation effects at high altitudes and performance of improved passive solar design- Case of Lhasa
}

\author{
Lingjiang Huang', Jian Kang² ( $ه)$ \\ 1. Department of Architecture, Wuhan University, Wuhan 430072, China \\ 2. UCL Institute for Environmental Design and Engineering, The Bartlett, University College London (UCL), London WC1H ONN, UK
}

\begin{abstract}
The solar incidence on an indoor environment and its occupants has significant impacts on indoor thermal comfort. It can bring favorable passive solar heating and can result in undesired overheating (even in winter). This problem becomes more critical for high altitudes with high intensity of solar irradiance, while received limited attention. In this study, we explored the specific overheating and rising thermal discomfort in winter in Lhasa as a typical location of a cold climate at high altitudes. First, we evaluated the thermal comfort incorporating solar radiation effect in winter by field measurements. Subsequently, we investigated local occupant adaptive responses (considering the impact of direct solar irradiance). This was followed by a simulation study of assessment of annual based thermal comfort and the effect on energy-saving potential by current solar adjustment. Finally, we discussed winter shading design for high altitudes for both solar shading and passive solar use at high altitudes, and evaluated thermal mass shading with solar louvers in terms of indoor environment control. The results reveal that considerable indoor overheating occurs during the whole winter season instead of summer in Lhasa, with over two-thirds of daytime beyond the comfort range. Further, various adaptive behaviors are adopted by occupants in response to overheating due to the solar radiation. Moreover, it is found that the energy-saving potential might be overestimated by 1.9 times with current window to wall ratio requirements in local design standards and building codes due to the thermal adaption by drawing curtains. The developed thermal mass shading is efficient in achieving an improved indoor thermal environment by reducing overheating time to an average of $62.2 \%$ during the winter and a corresponding increase of comfort time.
\end{abstract}

\section{Keywords}

thermal comfort, overheating, passive solar design, high altitude, Tibet, solar shading

\section{Article History}

Received: 29 April 2020

Revised: 08 November 2020

Accepted: 10 November 2020

(c) The Author(s) 2020

\section{Introduction}

\subsection{Background}

Solar radiation through a transparent envelope has a remarkable influence on the thermal comfort and indoor thermal environment. Unshaded glazing subjected to high solar irradiance can lead to both possible overheating (Arens et al. 2015), and unacceptable environmental conditions in certain portions of the indoor space (Marino et al. 2017a). With the extensive use of large glazing as an architectural component in modern buildings, the solar effect on indoor thermal comfort may cause more severe discomfort problems (Arens et al. 2018). On the other hand, in terms of passive solar designs, the fundamental premise is that the occupants can accept or at least tolerate the solar heat; otherwise, occupants draw shades to prevent overheating that reduces the expected use of solar gain (ASHRAE 2009).

A number of studies have investigated indoor thermal comfort near glazing incorporating with solar radiation effects. Khamporn and Chaiyapinunt (2014), Chaiyapinunt et al. (2005), and Singh et al. (2008) evaluated thermal comfort near a window for evaluation of the performance of different glazing types and glazing films, and the results

E-mail: j.kang@ucl.ac.uk 


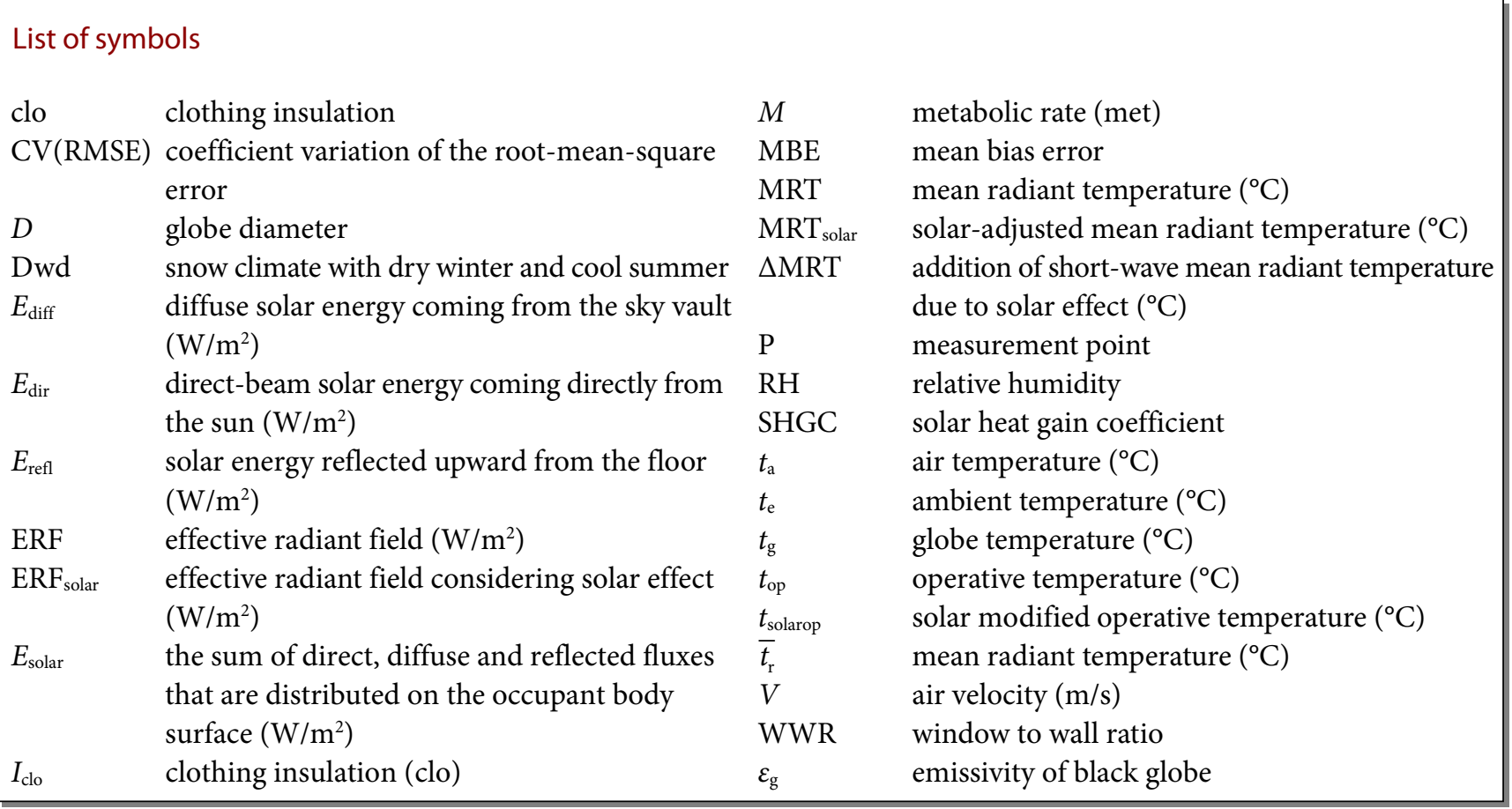

showed suitable glazing type could lower overheating risk due to the solar radiation. Chaiyapinunt and Khamporn (2020) further discussed the thermal comfort with various distances from the window glazing considering the solar effect. They found that thermal discomfort due to the transmitted direct solar is more dependent on the magnitude and direction of the solar beam radiation incident on a human body. Marino et al. (2015) evaluated annual indoor thermal comfort considering solar radiation, and found that solar radiation may cause notably unacceptable environmental conditions which might be ignored if solar radiation had not been taken into account. Bessoudo et al. (2010) compared the thermal environment near the glass façade between no shading device and Venetian blind. They revealed that overheating will occur in glazed perimeter spaces, even on cold sunny days without shading devices. Zomorodian and Tahsildoost (2017) assessed the window performance on indoor thermal comfort including a window to wall ratio (WWR), solar heat gain coefficient (SHGC), $U$-value, orientation, and shading, etc., and revealed that $U$-value and low SHGC can decrease overheating risk. Cappelletti et al. (2014) evaluated the performance of the glazing component on heating and cooling loads in different climates. The results showed that winter cooling needs might overcome heating needs in specific locations considering high SHGC, south orientation, and window size. Despite various focuses, it has been a consensus that solar radiation may cause considerable thermal discomfort problems in indoor space and should raise concerns.

Although there has been an increasing interest in solar effects on indoor thermal comfort, existing studies mostly addressed this issue in low altitude climates regarding window performance for the prevention of solar radiation. This issue receives relatively limited attention for high altitude locations regarding passive solar heating. For high altitudes, solar radiation has specific effects on the indoor environment. First, solar radiation is more crucial to the indoor environment at high altitude locations, where the intensity of direct solar irradiance exhibits a significant increase due to the "altitude effect" (Blumthaler et al. 1997; Blumthaler 2012). For instance, during winter, Lhasa (altitude $3650 \mathrm{~m}$ ) receives an average daily solar intensity of $4.7 \mathrm{kWh} / \mathrm{m}^{2}$, which is 1.7 times than that in Beijing (altitude $31 \mathrm{~m}$ ). Second, due to the low ambient temperature in winter and scarcity fossil energy, passive solar heat is highly recommended for improvement of indoor thermal environment and reducing heating load at high altitude locations such as Nepal and Tibet, China ( Bodach et al. 2014; Sun and Leng 2015; Nie et al. 2019). In Tibet, current local building codes related to energy efficiency require over $50 \%$ (or no less than $45 \%$ ) of the south WWR for direct use of solar gain (DB5400012016 2016), and the possible negative impact of direct solar gain on thermal comfort has not received enough attention.

\subsection{Objectives of this study}

Studies on the thermal comfort incorporating at high locations with solar radiation regarding passive solar heating are limited. This study aims to conduct a systematic examination in this area. In particular, we focus on (a) evaluation of the 
degree, duration, and spatial distribution of the overheating, (b) occupants' adaptive behaviors due to the solar radiation in winter in the case of Lhasa, (c) the impact of occupants' solar adjustment by drawing curtains, on energy consumption, and reassessment of the effectiveness of the current design standard for direct solar gain in local building codes and (d) how an improved passive solar heating technology can mitigate the overheating effects of the plateau climate. Lhasa, Tibet Autonomous Region is selected as the case for this study.

\subsection{Climatic condition of Lhasa}

Lhasa $\left(29.67^{\circ} \mathrm{N}, 91.13^{\circ} \mathrm{E}\right)$ is located at an altitude of $3600 \mathrm{~m}$ in Tibet Tibet Autonomous Region, of which the climate classification is snow climate with dry winter and cool summer (Dwd) in Koeppen-Geiger Climate classification (Kottek et al. 2006) and cold climate in the China Standard of Climatic Regionalization for Architecture (GB50178-93). The dominant climatic features include low ambient temperature, high diurnal temperature, low relative humidity $(\mathrm{RH})$, and high intensity of solar radiation with long solar duration. According to China standard weather data, the annual mean temperature in Lhasa is $8.3^{\circ} \mathrm{C}$, while this is approximately $-1.0^{\circ} \mathrm{C}$ during the winter period of December, January, and February. The daily lowest temperature can be as low as $-13{ }^{\circ} \mathrm{C}$ in the coldest month. The diurnal temperature of Lhasa is approximately $15{ }^{\circ} \mathrm{C}$ from $-9{ }^{\circ} \mathrm{C}$ to $6^{\circ} \mathrm{C}$ during winter months. Lhasa is very dry throughout the year. In winter, the average $\mathrm{RH}$ is very low at approximately $26.5 \%$, which is also a cause of the high diurnal temperature. The annual and winter mean global solar radiation in Lhasa is approximately $169 \mathrm{kWh} / \mathrm{m}^{2}$ and
$135 \mathrm{kWh} / \mathrm{m}^{2}$, respectively, which are twice higher than other cities at the same latitude. Additionally, the annual solar duration in Lhasa is equivalent to 2980 hours, and this is 777 hours in winter, which are both among the highest in China (Figure 1).

For a due-south glazing in Lhasa, the high solar stress is mainly between Dec and Feb, with solar altitude varying between $20^{\circ}$ and $45^{\circ}$. Moreover, direct solar exposure in winter is $538.1 \mathrm{kWh} / \mathrm{m}^{2}$, which accounts for $80.5 \%$ of the annual value (Figure 2). The sunrise and sunset hours on winter solstice day Dec 22 are 08:51 and 18:56 in standard time (Time zone 8 ) with approximately ten solar hours.

1.4 Problems in indoor environment resulted from present passive solar heating in Lhasa

Due to the abundance of solar energy, passive solar heating is mandatory in Tibet and therefore integrated into local building codes for constructing low-energy buildings and improving the indoor thermal environment. Despite the benefit of passive solar gain and widely adopted direct-gain system in Lhasa, occupants in office buildings are found to prevent solar radiation indoor by drawing curtains in south-oriented rooms.

Two surveys were conducted in Lhasa in winter for an understanding of this problem. First, a field survey was conducted for information on solar adjustment by occupants in office buildings. A total of 30 buildings were selected, with unit office rooms and direct solar gain window or a combination of Trombe wall with a direct-gain window.

The results reveal that internal curtains shaded over $80 \%$ of southern windows during sunny winter days, and over $50 \%$ of windows were fully shaded (Figure 3 ). Further,

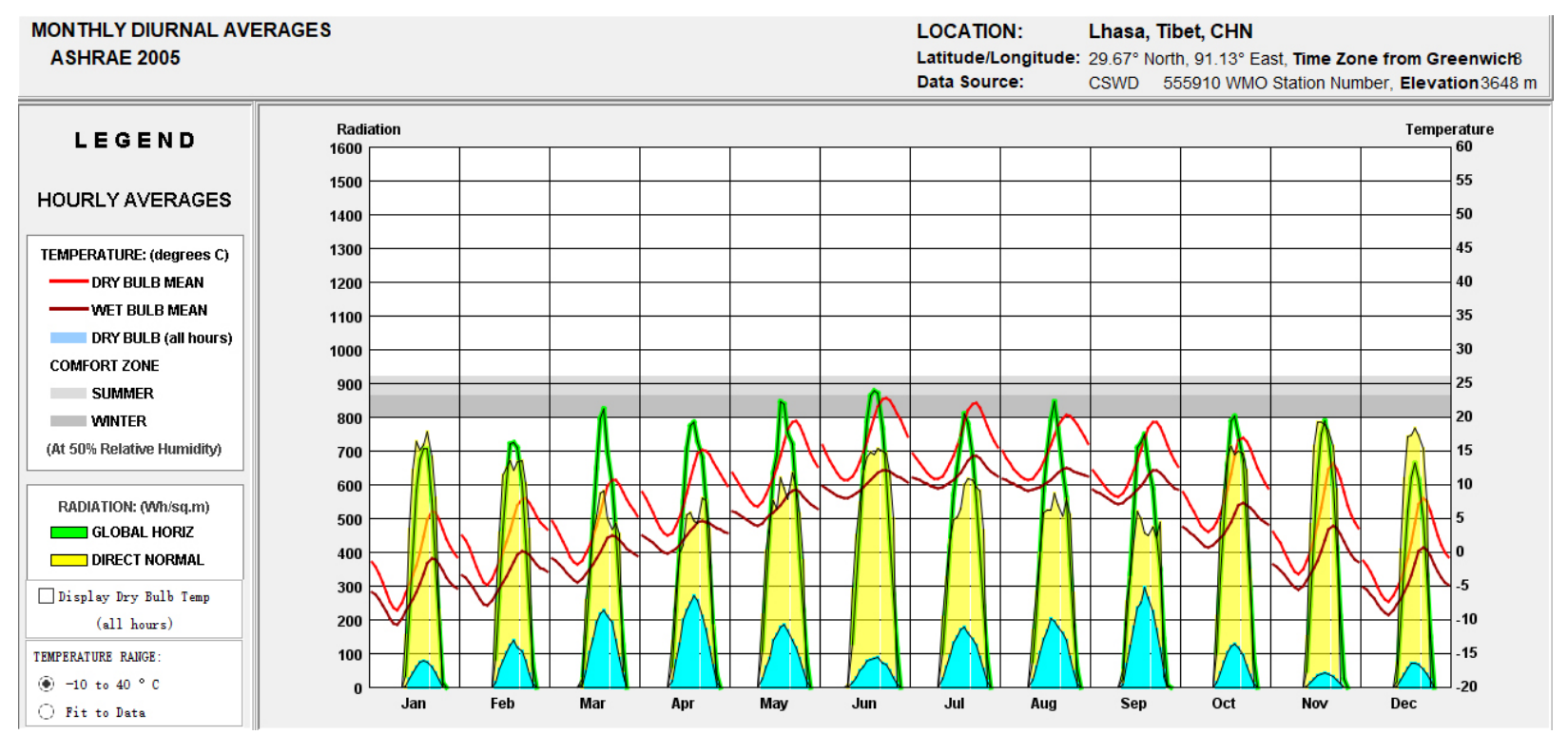

Fig. 1 Meteorological data of Lhasa (source: Milne 2016) 

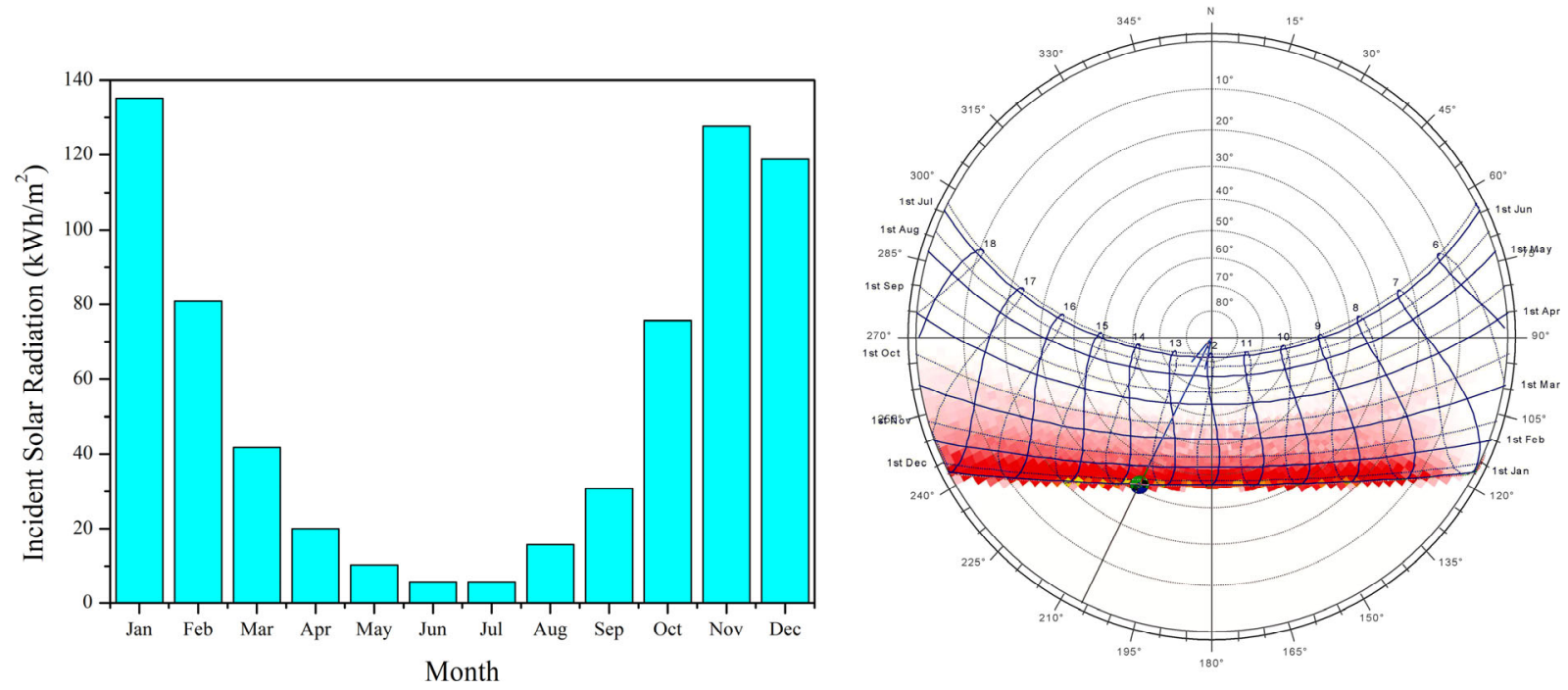

Fig. 2 Distribution of mean monthly solar radiation and sun-path diagram of Lhasa

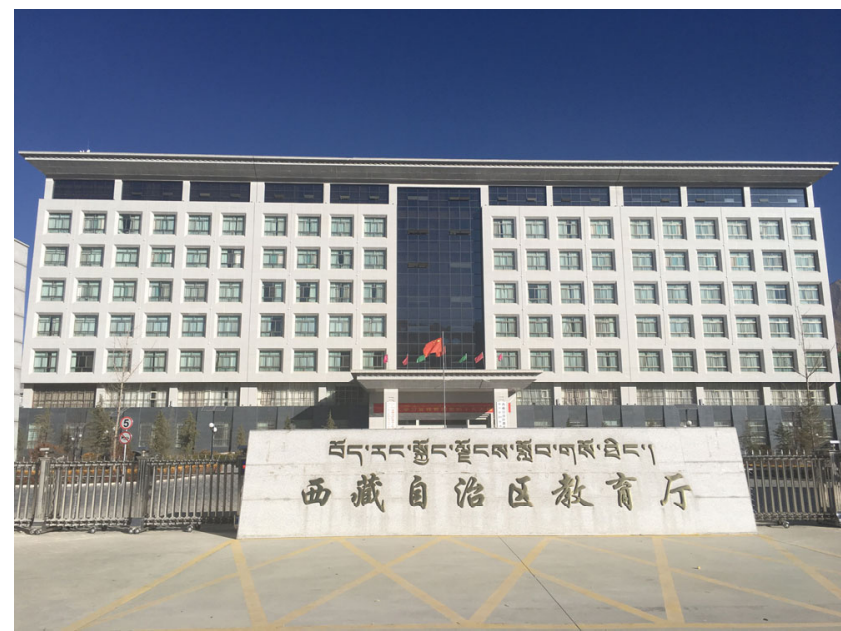

Fig. 3 A typical office building in Lhasa on a sunny winter day (during working hours) for some buildings, over $90 \%$ of windows were found to be fully shaded. Meanwhile, different ways of curtain closure were adopted to achieve various coverage of windows with the use of internal curtains (Figure 4), which implies that the occupants attempted to achieve a balance of solar heat gain, thermal and visual discomfort caused by direct solar irradiance.

Next, a preliminary further on-site questionnaire was survey was conducted for a general understanding of subjective evaluation of thermal comfort considering solar effect. For easy understanding of the structure of the scale, a simplified 3-point questionnaire was adopted. The survey showed that in south-facing rooms, over $52.8 \%$ of the participants experienced thermal discomfort from overheating, of which $23.6 \%$ also complained that direct sunlight caused a feeling of skin burn or skin discomfort. 13.8\% reported
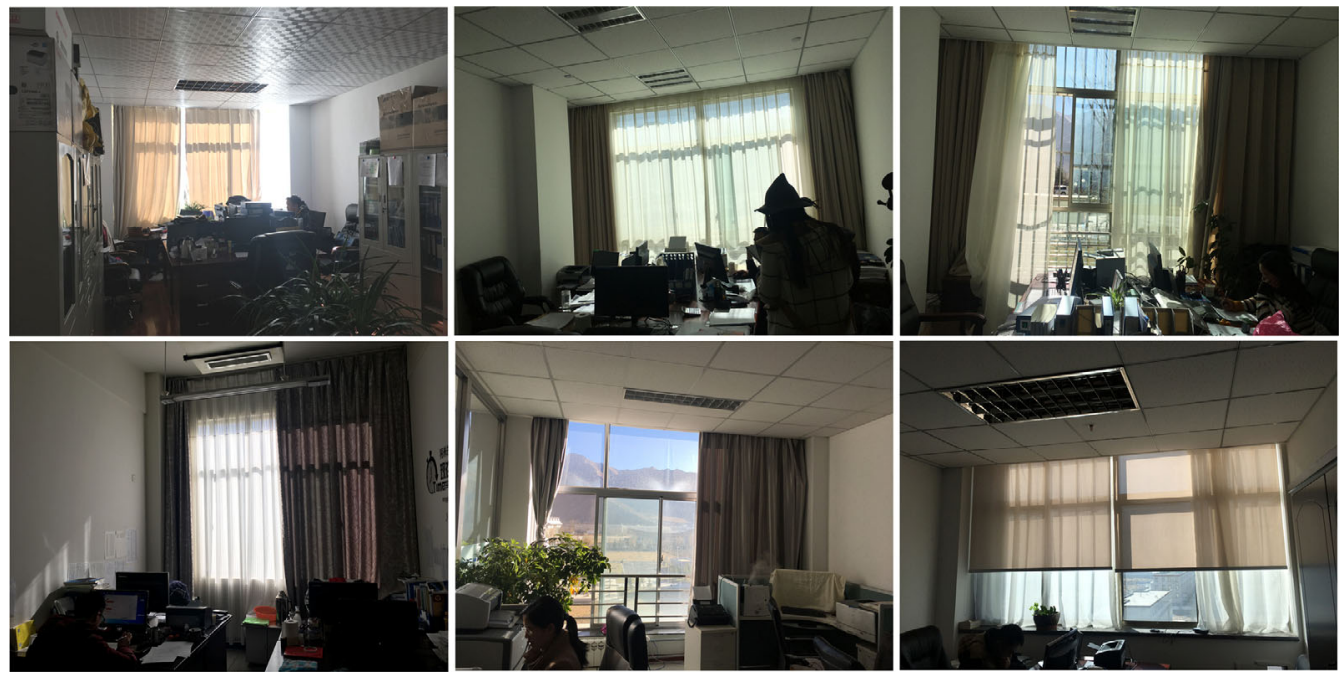

Fig. 4 Various ways of window shading with the use of curtains in winter 
that direct solar radiation might also cause headaches or eye discomfort. Only $22.6 \%$ reported non-discomfort. It is also found that the number of thermal complaints tends to increase when the indoor air temperature exceeds $20^{\circ} \mathrm{C}$. Also, occupants' solar adjustment by drawing curtains is against the expected requirement for the utilization of direct solar heat gain. Thus, the heating load may be underestimated when actual passive solar gain overestimated, indicating a need to reassess the efficiency of WWR requirements in Tibetan local building codes based on passive solar gain and occupants' solar adjustment.

\section{Research methods}

The study involved four steps (Figure 5). In the first step, we conducted field measurements of the indoor thermal environment to explore the degree of overheating caused by winter solar irradiance. In the second step, we conducted an on-site investigation on occupants' adaptive behaviors in response to solar radiation. In the third step, we explored thermal (dis)comfort due to the solar effect by the simulation to evaluate the phenomenon of overheating on an annual basis, and the temporal and spatial distributions of the thermal indoor environment. Subsequently, the heating load due to the occupant shading behavior compared to the benchmark based on the local building code. Finally, in the fourth step, a design approach is proposed, and the effectiveness of the design prototype was tested from the aspect of thermal environment control, which integrates the utilization of both passive solar heat and solar shading.

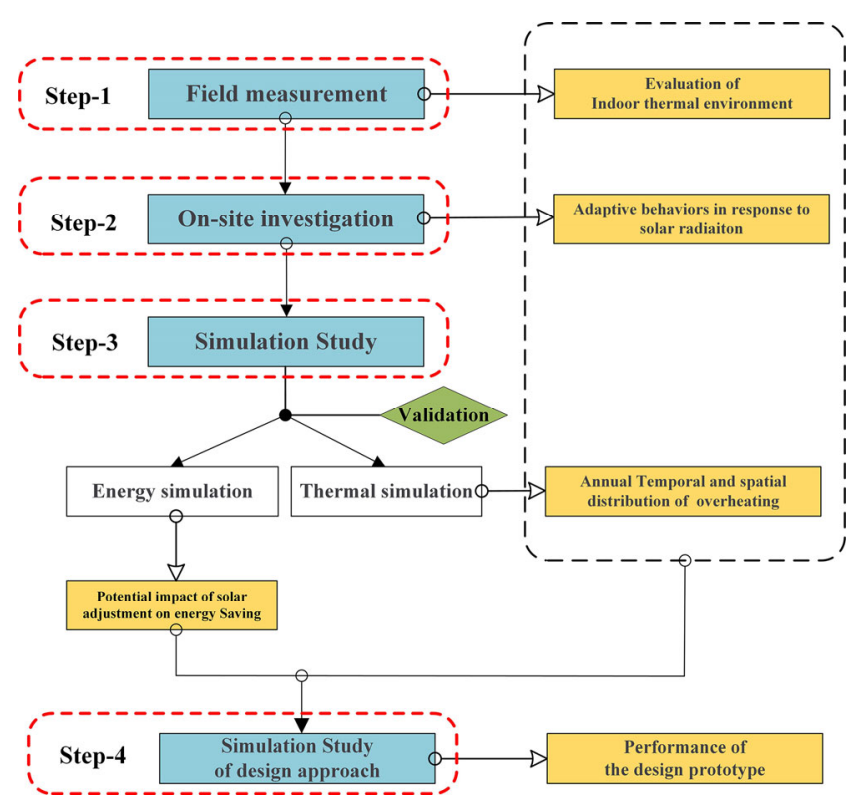

Fig. 5 Workflow of the study

\subsection{Measurement setup}

Field measurements were conducted to provide an evaluation of the thermal environment in a typical office-unit room in Lhasa in winter, keeping in mind the effects of short-wave radiation. The office is located on the fourth floor of a five-story building and oriented due south with a WWR of $60 \%$ (Figure 6). The window is comprised of a single glazing with an aluminum frame. The width, depth, and height of the room were $3.8,7.4$, and $2.8 \mathrm{~m}$, respectively, and the window sill was $0.9 \mathrm{~m}$ in height. The room contained no mechanical ventilation or heating. Four black-globe thermometers were used to measure the mean radiant temperature (MRT) of the irradiated and unirradiated areas in the room. The convective heat transfer by air movement was ignored in the measurement of the MRT because the air velocity was slow (Marino et al. 2017b). An indoor Air Quality System (JT-IAQ 2.3) was used to measure the indoor environmental parameters, including the air temperature, air velocity, relative humidity, and black-globe temperature at an interval of 30 minutes. Further, two data loggers were used for measurements of the horizontal and vertical solar irradiances at an interval of 60 minutes, which were utilized for the calculation of the direct irradiance. The equipment was placed along the centerline of the room, with sensors positioned at $1.1 \mathrm{~m}$ above the floor (around the height of a standing person). ISO 7726:1998 (ISO 7726:1998 1998) was referred for the measurement. However, two factors need to be considered while measuring indoors. First, the short-wave radiation at the irradiated point might be overestimated to represent regular clothing. However, in winter, overestimation could be reduced as occupants generally adopt dark clothing. Second, only one vertical measurement point was set for the measurement of air temperature, air

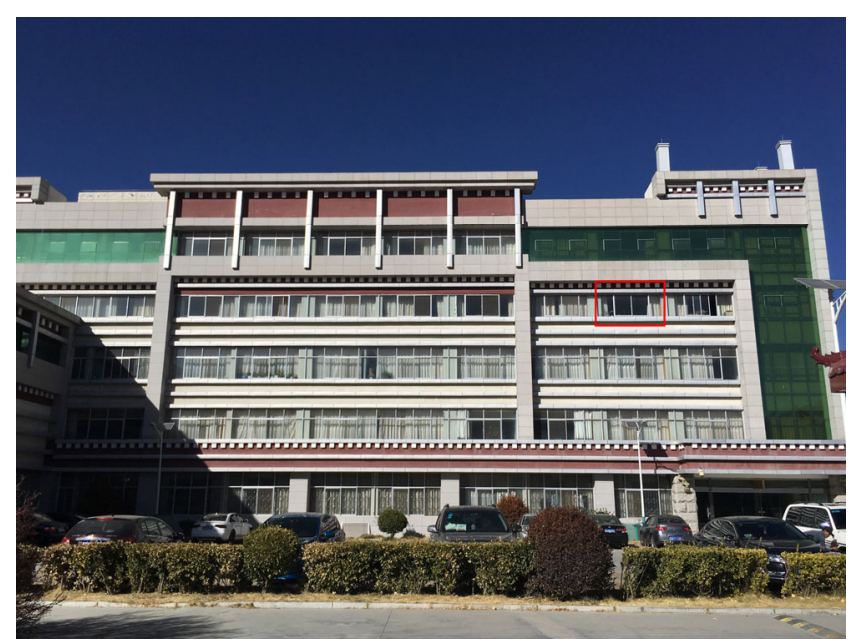

Fig. 6 Building and location of the office room utilized for measurement 
velocity, relative humidity, and black-globe temperature, respectively, which can cause inaccuracy in a heterogeneous environment. Since the interest of this study is the comparison of the conditions experienced by the occupants, the measurement point $1.1 \mathrm{~m}$ from the floor is considered representative of occupant experiences in the test room. For the outdoor variables, a data logger was used for the measurement of ambient temperature and humidity. The data logger was placed in a shaded and covered place on the roof of the building.

All measuring instruments were given $24 \mathrm{~h}$ at the measurement site for settlement. The measurement period for both indoor and outdoor variables lasted for over 40 consecutive days, and data between Dec $23^{\text {rd }}, 2017$ to Jan $31^{\text {st }}, 2018$ were used for analysis. During the measurements, the curtains remained open such that direct solar radiation enters the room (Figure 7). The information on the technical parameters of the instruments is listed in Table 1. For the calculation of MRT using the measured parameters, the equation for natural convection from ISO 7726 is used:

$$
\begin{aligned}
\bar{t}_{\mathrm{r}}= & {\left[\left(t_{\mathrm{g}}+273\right)^{4}+\frac{0.25 \times 10^{8}}{\varepsilon_{\mathrm{g}}}\left(\frac{\left|t_{\mathrm{g}}-t_{\mathrm{a}}\right|}{D}\right)^{1 / 4}\right.} \\
& \left.\times\left(t_{\mathrm{g}}-t_{\mathrm{a}}\right)\right]^{1 / 4}-273
\end{aligned}
$$

where $\bar{t}_{\mathrm{r}}$ is the mean radiant temperature $\left({ }^{\circ} \mathrm{C}\right) ; t_{\mathrm{g}}$ is the measured globe temperature $\left({ }^{\circ} \mathrm{C}\right) ; t_{\mathrm{a}}$ is the measured air temperature $\left({ }^{\circ} \mathrm{C}\right) ; D$ is the globe diameter which is $0.15 \mathrm{~m}$ used in the measurement; and $\varepsilon_{\mathrm{g}}$ is the emissivity which is

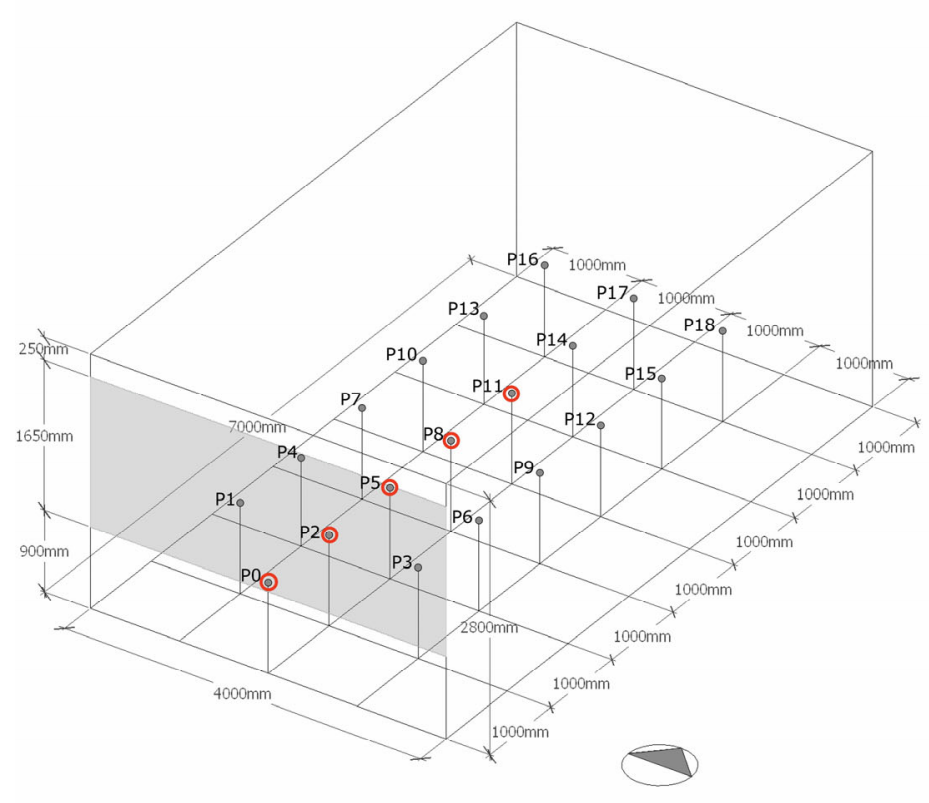

(a)

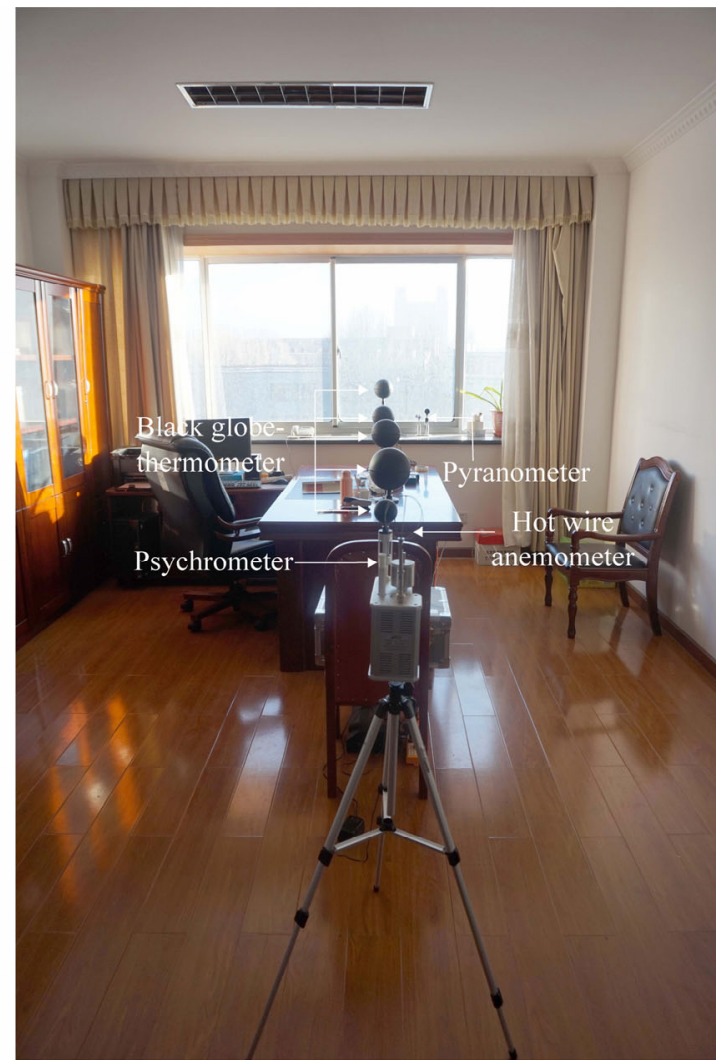

(b)

Fig. 7 Experimental setup: (a) locations of measurement points; (b) measurement setup

Table 1 Technical specifications of measuring equipment

\begin{tabular}{cccccc}
\hline Measured parameter & Probe type & Equipment type & Measured range & Accuracy & Location \\
\hline Air temperature & Psychrometer & JT-IAQ 2.3 & $5-60{ }^{\circ} \mathrm{C}$ & $\pm 0.5^{\circ} \mathrm{C}$ & Working station (1.1 m above the floor) \\
\hline Relative humidity & Psychrometer & JT-IAQ 2.3 & $0-100 \%$ & $\pm 1.5 \% \mathrm{RH}$ & Working station (1.1 m above the floor) \\
\hline Air velocity & Hot-wire anemometer & JT-IAQ 2.3 & $0.05-5 \mathrm{~m} / \mathrm{s}$ & $\pm(0.03 \mathrm{~m} / \mathrm{s}+2 \%$ reading) & Working station (1.1 m above the floor) \\
\hline Globe temperature & Black-globe thermometer & JTTH-3.5 & $5-120^{\circ} \mathrm{C}$ & $\pm 0.5^{\circ} \mathrm{C}$ & Working station $(1.1 \mathrm{~m}$ above the floor) \\
\hline Solar radiation & Pyranometer & DT185 & $0-1999 \mathrm{~W} / \mathrm{m}^{2}$ & $\pm 5 \%$ & On the window sill \\
\hline
\end{tabular}


0.95 for black globe thermometer.

2.2 Prediction method for thermal comfort considering the solar effect

\subsubsection{Prediction method}

A simulation study was employed for the prediction of indoor thermal environments on an annual basis. First, DesignBuilder (version 4.2) was used to simulate the indoor air temperature $\left(t_{\mathrm{a}}\right)$ and MRT. Later, the SolarCal model embedded in the Ladybug interface (version 0.064) was used to run the computations of the solar adjusted MRT $\left(\mathrm{MRT}_{\text {solar }}\right)$ considering the effect of solar radiation by the addition of short-wave MRT $(\Delta \mathrm{MRT})$. The SolarCal model is a whole-body model for calculation of the impact of solar gain on occupants and is proposed as an evaluation method for thermal comfort considering solar effect in the early design stage (Arens et al. 2015) and adopted in ASHRAE Standard 55-2017 (ASHRAE 2017). The EnergyPlus weather data of Lhasa was used for the predictions.

In the SolarCal model, solar gain to the human body is calculated using the effective radiant field (ERF), a measure of the net radiant energy flux to or from the human body.

ERF is calculated by the following equation:

$\mathrm{ERF}=f_{\mathrm{eff}} h_{\mathrm{r}}\left(\overline{t_{\mathrm{r}}}-t_{\mathrm{a}}\right)$

where $f_{\text {eff }}$ is the fraction of the body surface exposed to radiation from the environment; $h_{\mathrm{r}}$ is the radiation heat transfer coefficient; $t_{\mathrm{a}}$ is the air temperature $\left({ }^{\circ} \mathrm{C}\right)$; and $\bar{t}_{\mathrm{r}}$ is the mean radiant temperature $\left({ }^{\circ} \mathrm{C}\right)$.

When the solar radiation on the human body is considered, $\mathrm{ERF}_{\text {solar }}$ is calculated by the following equation:

$\mathrm{ERF}_{\text {solar }}=\frac{\alpha_{\mathrm{SW}}}{\alpha_{\mathrm{LW}}} E_{\mathrm{solar}}$

where $E_{\text {solar }}$ is the sum of three fluxes that are distributed on the occupant body surface $\left(\mathrm{W} / \mathrm{m}^{2}\right)$ including the diffuse solar energy coming from the sky vault $\left(E_{\text {diff }}\right)$, the solar energy reflected upward from the floor $\left(E_{\text {refl }}\right)$, and the direct-beam solar energy coming directly from the sun $\left(E_{\mathrm{dir}}\right)$. And $\alpha_{\mathrm{SW}}$ is the short-wave absorptivity and $\alpha_{\mathrm{LW}}$ is the long-wave absorptivity.

The addition of short-wave MRT ( $\triangle \mathrm{MRT})$ is, therefore calculated by the following equation:

$$
\Delta \mathrm{MRT}=\frac{\alpha_{\mathrm{SW}}}{\alpha_{\mathrm{LW}} f_{\mathrm{eff}} h_{\mathrm{r}}} \times E_{\mathrm{solar}}
$$

In the computation of $\mathrm{MRT}_{\text {solar, }}$ the body posture of the mannequin mesh is set in standing position, and body location is in 90 degrees in relation to the sun.

\subsubsection{Description of the studied room}

A room module representing a typical office space was used for the prediction, with dimensions of $4.0 \mathrm{~m}$ (width), $7.0 \mathrm{~m}$ (depth), $2.8 \mathrm{~m}$ (height) with a WWR of $60 \%$ to the south. A grid of $1 \mathrm{~m}$ by $1 \mathrm{~m}$ was applied to represent the room space. The exterior envelopes were set to be adiabatic except the southern and northern walls. No artificial heating or cooling was considered, and no mechanical ventilation was set. Therefore, the indoor air velocity was assumed to be less than $0.2 \mathrm{~m} / \mathrm{s}$. The assumed parameters for the simulation are listed in Table 2 .

Table 2 Parameters used for simulation

\begin{tabular}{llc}
\hline \multicolumn{1}{c}{ Parameters } & \multicolumn{1}{c}{ Description } & Value \\
\hline Metabolic rate (met) & Light office work & 0.9 \\
\hline Clothing insulation (clo) & Winter clothing & 1.0 \\
\hline & $\begin{array}{l}\text { South wall (300mm aerated concrete } \\
\text { plastered both sides) }\end{array}$ & 0.477 \\
$U$-value $\left(\mathrm{W} /\left(\mathrm{m}^{2} \cdot \mathrm{K}\right)\right)$ & $\begin{array}{l}\text { North wall (200mm aerated concrete } \\
\text { plastered both sides) }\end{array}$ & 0.67 \\
& Glazing & 5.718 \\
\hline SHGC & Glazing (single clear 6mm) & 0.766 \\
\hline
\end{tabular}

\subsection{Investigation on adaptive response to the solar effect}

The on-site investigation was conducted from Dec $8^{\text {th }}$ till Dec $20^{\text {th }}$ of 2017, when similar weather conditions prevailed. Seventy-two occupants in sedentary work were engaged, from 12 randomly selected modern office buildings on the Southside. The participants were asked what measures they would take when they feel uncomfortably warm due to the sunlight, and were given options of drawing a curtain, change of cloth, moving position, and other measures. The purpose of the investigation was to identify participant adaptive behaviors response towards direct solar radiation in an office environment during winter. The participants were asked to answer the questions according to their personal experience. Of the 72 respondents, $56.9 \%$ were male, and $43.1 \%$ were female, and the subjects' age ranges between 20 to 60 years. The information regarding the surveyed participants is summarised in Table 3.

\subsection{Setup of energy simulation}

Simulations using DesignBuilder (version 4.2) were conducted to explore the impact of the adopted solar adjustment on energy consumption and the effectiveness of the current requirements of WWR in local design standards and building codes. The same room module in Section 2.1 was used for analysis, and two scenarios were analyzed to 
Table 3 Information on the surveyed participants.

\begin{tabular}{ccc}
\hline & & Percentage \\
\hline \multirow{3}{*}{ Age(years) } & $<24$ & $43.1 \%$ \\
& $25-35$ & $38.9 \%$ \\
& $36-45$ & $11.1 \%$ \\
Gender & $46-60$ & $5.6 \%$ \\
\hline \multirow{2}{*}{ Ethnic group } & Male & $56.9 \%$ \\
& Female & $43.1 \%$ \\
\hline & Han & $70.8 \%$ \\
& Tibetan & $26.5 \%$ \\
\hline
\end{tabular}

explore the impact of occupants' solar adjustment on energy performance. The first scenario (A) has a general horizontal strip window with WWR of $60 \%$ according to local design standards and no shading by drawing curtains, for evaluating the energy performance with direct solar gain. And the second scenario (B) is similar to (A) but equipped with close-weaved light drapes, for evaluating the solaradjustment strategy of occupants by drawing curtains. The criteria for incoming solar radiations to trigger the shading operation varies from 94.5 to $233 \mathrm{~W} / \mathrm{m}^{2}$ in the literature (Newsham 1994; Lee and Selkowitz 1995); In this study, the solar set-point to active the shading is defined at $200 \mathrm{~W} / \mathrm{m}^{2}$. In the simulation, the heating mode was set as electric storage heaters with a mixed distribution model of air temperature, and the heating set-point temperature was $18^{\circ} \mathrm{C}$. Electric lighting was assumed active when the daylight level was below $500 \mathrm{~lx} / \mathrm{m}^{2}$. Simulations were performed for the heating period in Lhasa (Oct $30^{\text {th }}$ to Mar $8^{\text {th }}$ ).

\subsection{Validation method of simulation}

The reliability of the simulation method was validated. For the prediction of thermal condition with and without solar effect, two test points (P2 and P11 shown in Figure 7) representing the irradiated and unirradiated areas, respectively, were selected for the validation. P2 was $1 \mathrm{~m}$ away from the window for the validation of the simulated $\mathrm{MRT}_{\text {solar }}$ while P11 was set in the center of the room for acquiring MRT. For the energy simulation, simulated data of $t_{\mathrm{a}}$ was validated against the hourly measured data. The measured data of the environmental parameters for Jan 2018 were fed into the EnergyPlus weather data for computation, and the parameters include the hourly ambient air temperature, ambient relative humidity, and direct radiation.

The method of mean bias error (MBE) and coefficient variation of the root-mean-square error [CV(RMSE)] using Eqs. (5) and (6) are used for validation. Meanwhile, key statistic values, including average, median, minimum, and maximum values, are compared for reference.

$$
\begin{aligned}
& \mathrm{MBE}=\frac{\sum_{i=1}^{N}\left(M_{i}-S_{i}\right)}{\sum_{i=1}^{N} M_{i}} \\
& \mathrm{CV}(\mathrm{RMSE})=\frac{\sqrt{\sum_{i=1}^{N}\left[\frac{\left(M_{i}-S_{i}\right)^{2}}{N}\right]}}{\frac{1}{N} \sum_{i=1}^{N} M_{i}}
\end{aligned}
$$

where $M_{i}$ is the measured data at a given hour; $S_{i}$ is the simulated data at a given hour, and $N$ is the count of measurements. The lower values of MBE and CV(RMSE) mean good calibration, and the acceptance criteria to consider the simulated data to be calibrated is $\pm 10 \%$ for MBE and $30 \%$ for CV(RMSE) using hourly data as defined in ASHRAE Guideline 14-2014 (ASHRAE 2002).

The MBE and CV(RMSE) values of the indices are listed in Table 4. It can be seen that for $t_{\mathrm{a}}$ and MRT, the MBE and $\mathrm{CV}$ (RMSE) are within the stipulated range, indicating a proper calibration; for $\mathrm{MRT}_{\text {solar, }}$, the MBE is slightly higher than the defined upper limit by $0.1 \%$, while CV(RMSE) is within the required range.

Figure 8 further exhibits the comparison of the measured and calculated $\mathrm{MRT}_{\text {solar }}$ for the week between Jan $22^{\text {nd }}$ to Jan $28^{\text {th }}$ (2018). It can be seen that there is a similar pattern between the measured and calculated data, where both

\begin{tabular}{|c|c|c|c|c|c|c|}
\hline Parameters & \multicolumn{2}{|c|}{$t_{\mathrm{a}}$} & \multicolumn{2}{|c|}{ MRT } & \multicolumn{2}{|c|}{$\mathrm{MRT}_{\text {solar }}$} \\
\hline MBE & \multicolumn{2}{|c|}{$-1.6 \%$} & \multicolumn{2}{|c|}{$-5.0 \%$} & \multicolumn{2}{|c|}{$10.1 \%$} \\
\hline CV(RMSE) & \multicolumn{2}{|c|}{$4.4 \%$} & \multicolumn{2}{|c|}{$7.9 \%$} & \multicolumn{2}{|c|}{$15.7 \%$} \\
\hline & Measured & Simulated & Measured & Simulated & Measured & Simulated \\
\hline $\operatorname{Max}\left({ }^{\circ} \mathrm{C}\right)$ & 22.0 & 21.7 & 22.1 & 21.9 & 42.8 & 43.1 \\
\hline $\operatorname{Min}\left({ }^{\circ} \mathrm{C}\right)$ & 13.3 & 12.5 & 12.8 & 13.1 & 10.3 & 13.1 \\
\hline Average $\left({ }^{\circ} \mathrm{C}\right)$ & 17.4 & 17.7 & 17.2 & 18.1 & 22.1 & 24.5 \\
\hline Median $\left({ }^{\circ} \mathrm{C}\right)$ & 17.2 & 17.8 & 16.9 & 18.1 & 16.0 & 19.1 \\
\hline
\end{tabular}

Table 4 MBE, CV (RMSE) and statistic values 


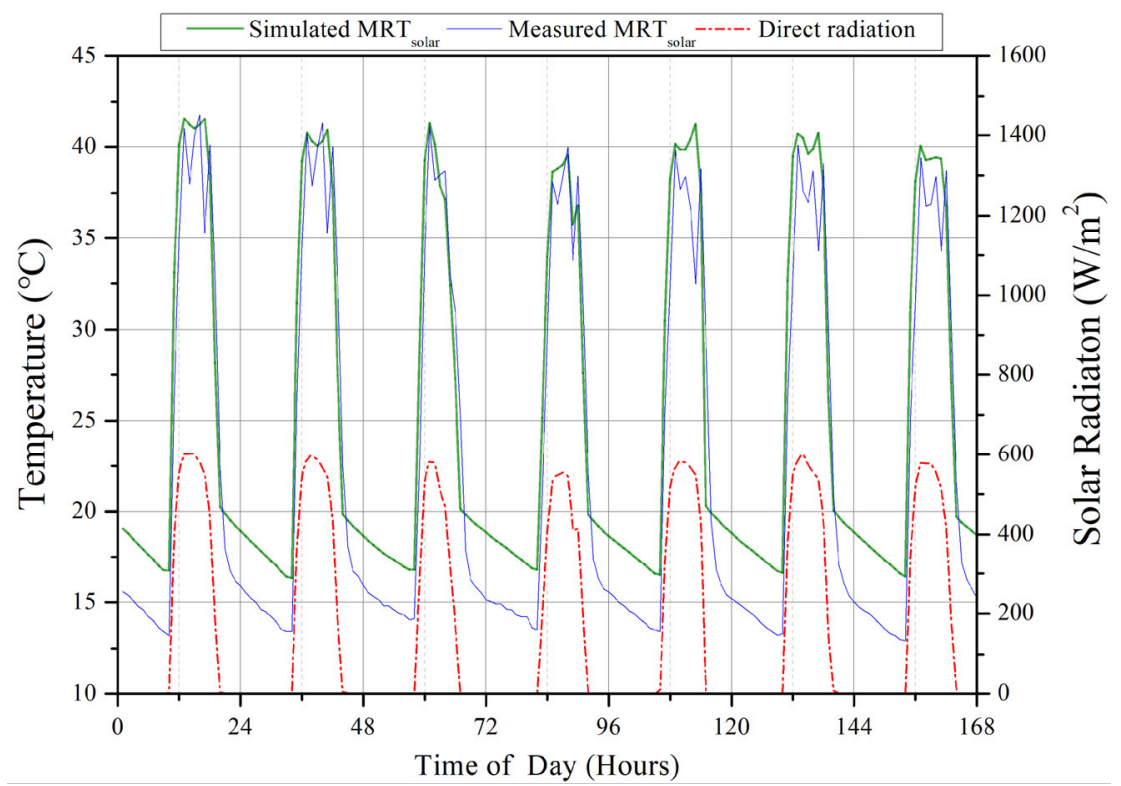

Fig. 8 Comparisons of measured and simulated $\mathrm{MRT}_{\text {solar }}$

curves are observed to have peak values exceeding $40{ }^{\circ} \mathrm{C}$ with the peaks occurring during the mid-day central hours of high solar radiation.

In the experimental set-up, a sphere is used to measure the black-globe temperature for the calculation of $\mathrm{MRT}_{\text {solar, }}$, while in the simulation, a standing mannequin was used. The difference in geometrical shape might cause some inconformity during periods of radiation. Moreover, during periods of no direct radiation, the simulated data is higher than the measured data that should cause the discretization between measured and simulated data, resulting from the radiant heat loss to the glazing not accounted in the model. In general, the simulated data of all three parameters are considered calibrated, and the proposed simulation method is deemed to be acceptable for the prediction of indoor thermal condition and energy simulation.

\subsection{Index and criteria for the objective evaluation}

\subsubsection{Index for evaluation}

The study considers air temperature and radiant temperature as the key factors affecting thermal comfort. Thus, the concept of operative temperature $\left(t_{\mathrm{op}}\right)$ is used for the evaluation. $t_{\mathrm{op}}$ is a single value that combines air temperature and mean radiant temperature used for free-running buildings with no heating system (De Dear and Brager 1998). It is both suggested for the evaluation of thermal sensation in a cold climate (Wang 2004), and adopted for expression of comfort temperatures in the adaptive sections in both ASHRAE 55 and the CEN EN15251s. The index of solar adjusted operative temperature $\left(t_{\text {solarop }}\right)$ is employed for the objective evaluation of the indoor thermal environment. $t_{\text {solarop }}$ is the modified operative temperature and considers $\mathrm{MRT}_{\text {solar }}$ for calculation instead of MRT that does not take into consideration the heat load of solar radiation. The SolarCal model is employed for the calculation of $\triangle \mathrm{MRT}$ (ASHRAE 2017), and the equations of solar adjusted $\mathrm{MRT}_{\text {solar }}$ and the modified operative temperature are as follows:

$$
\begin{gathered}
\mathrm{MRT}_{\text {solar }}=\mathrm{MRT}+\Delta \mathrm{MRT} \\
t_{\text {solarop }}=\left(t_{\mathrm{a}}+\mathrm{MRT}_{\text {solar }}\right) / 2
\end{gathered}
$$

where $t_{\text {solarop }}$ is the solar modified operative temperature, $t_{\mathrm{a}}$ is the indoor air temperature, $\mathrm{MRT}_{\text {solar }}$ is the solar modified radiant temperature, and $\triangle \mathrm{MRT}$ is the additional radiant temperature for solar effect.

\subsubsection{Criteria for evaluation}

Existing studies and international and domestic standards propose various ranges of thermal comfort for Lhasa. In this study, the assessment is for the condition of a freerunning building; therefore, criteria for adaptive thermal comfort are referred to for evaluation.

Adaptive thermal comfort zones can be defined using the adaptive thermal comfort model proposed in ASHRAE standard 55 (ASHRAE 2017). Yang et al. (2013) and Yu et al. (2017) defined the neutral temperature and adaptive thermal ranges for winter and summer in Lhasa based on-site surveys. The indoor design temperature in Tibetan local building code is listed in (DB54/0015-2007 2007). The ranges of thermal comfort for winter and summer are displayed in Table 5. 
Table 5 Ranges of adaptive thermal comfort for Lhasa

\begin{tabular}{|c|c|c|c|c|c|c|c|}
\hline \multirow[b]{2}{*}{ Source } & \multicolumn{3}{|c|}{ Winter $\left({ }^{\circ} \mathrm{C}\right)$} & \multicolumn{3}{|c|}{ Summer $\left({ }^{\circ} \mathrm{C}\right)$} & \multirow[b]{2}{*}{ Note } \\
\hline & Lower & Neutral & Upper & Lower & Neutral & Upper & \\
\hline $\begin{array}{c}\text { ASHRAE } \\
\text { adaptive model }\end{array}$ & - & - & - & 20.1 & 22.6 & 25.1 & $\begin{array}{l}\text { Prevailing mean outdoor temperature is calculated with weather } \\
\text { data of Lhasa of Jun, July, and August (epw weather file) }\end{array}$ \\
\hline Yang et al. 2013 & 13.6 & 18.9 & 24.2 & 16.9 & 23.3 & 29.7 & Plateau climate (Lhasa) $80 \%$ thermal acceptability \\
\hline Yu et al. 2017 & 10.18 & & 22.91 & 9.36 & & 21.74 & $\begin{array}{l}\mathrm{RH}=30 \% \text { for winter; } \\
\mathrm{RH}=70 \% \text { for summer }\end{array}$ \\
\hline $\begin{array}{l}\text { DB54/0015-2007 } \\
\quad 2007\end{array}$ & 14 & & 24 & & & & Indoor design temperature for solar heating space \\
\hline ASHRAE 2017 & 21.3 & & 25.6 & & 24.6 & 27.7 & $\begin{array}{l}\text { Steady thermal environment } M=1.0-1.3 \text { met, } V \leq 0.1 \mathrm{~m} / \mathrm{s} \text {, } \\
\mathrm{RH}=20 \%, I_{\mathrm{clo}}=1.0 \text { clo winter and } 0.5 \text { clo summer }\end{array}$ \\
\hline
\end{tabular}

For the study setting, the prevailing mean outdoor temperature is $3^{\circ} \mathrm{C}$, which is significantly below the specified limit proposed in ASHRAE 55, therefore, a previous study in Lhasa is referred for the definition of the thermal comfort range. For the interest of this study, a conservative upper limit for winter is defined as $24.2^{\circ} \mathrm{C}$, and $29.7^{\circ} \mathrm{C}$ for summer. Overcooling in winter is defined as $13.6^{\circ} \mathrm{C}$. Thus, with the index of $t_{\text {solarop }}$, the criteria for the assessment of the indoor thermal condition is defined as winter overheating occurs when $t_{\text {solarop }}>24.2{ }^{\circ} \mathrm{C}$, comfort when $13.6{ }^{\circ} \mathrm{C} \leq t_{\text {solarop }}$ $\leq 24.2{ }^{\circ} \mathrm{C}$ and winter overcooling when $t_{\text {solarop }}<13.6^{\circ} \mathrm{C}$, while summer overheating occurs when $t_{\text {solarop }}>29.7^{\circ} \mathrm{C}$. In this study, the winter period is defined as the four months of Nov, Dec, Jan, and Feb, while the summer period is the three months of Jun, Jul, and Aug.

\section{Results and discussion}

\subsection{Evaluation of thermal comfort}

\subsubsection{Evaluation by field measurement}

First, the field measurement data were interpreted to assess the condition of the thermal environment during the measurement period. As can be observed from Figure 9, the measured indoor air temperature $\left(t_{\mathrm{a}}\right)$ and black globe temperature $\left(t_{\mathrm{g}}\right)$ exhibit regular daily variations during the measurement period. The daily ambient temperature $\left(t_{\mathrm{e}}\right)$ fluctuates from around -5 to $+10{ }^{\circ} \mathrm{C}$, while $t_{\mathrm{a}}$ shows a diurnal range from around 15 to $22{ }^{\circ} \mathrm{C}$. Two points are selected for comparison of irradiated and unirradiated position. P2 represents the irradiated position, and P11

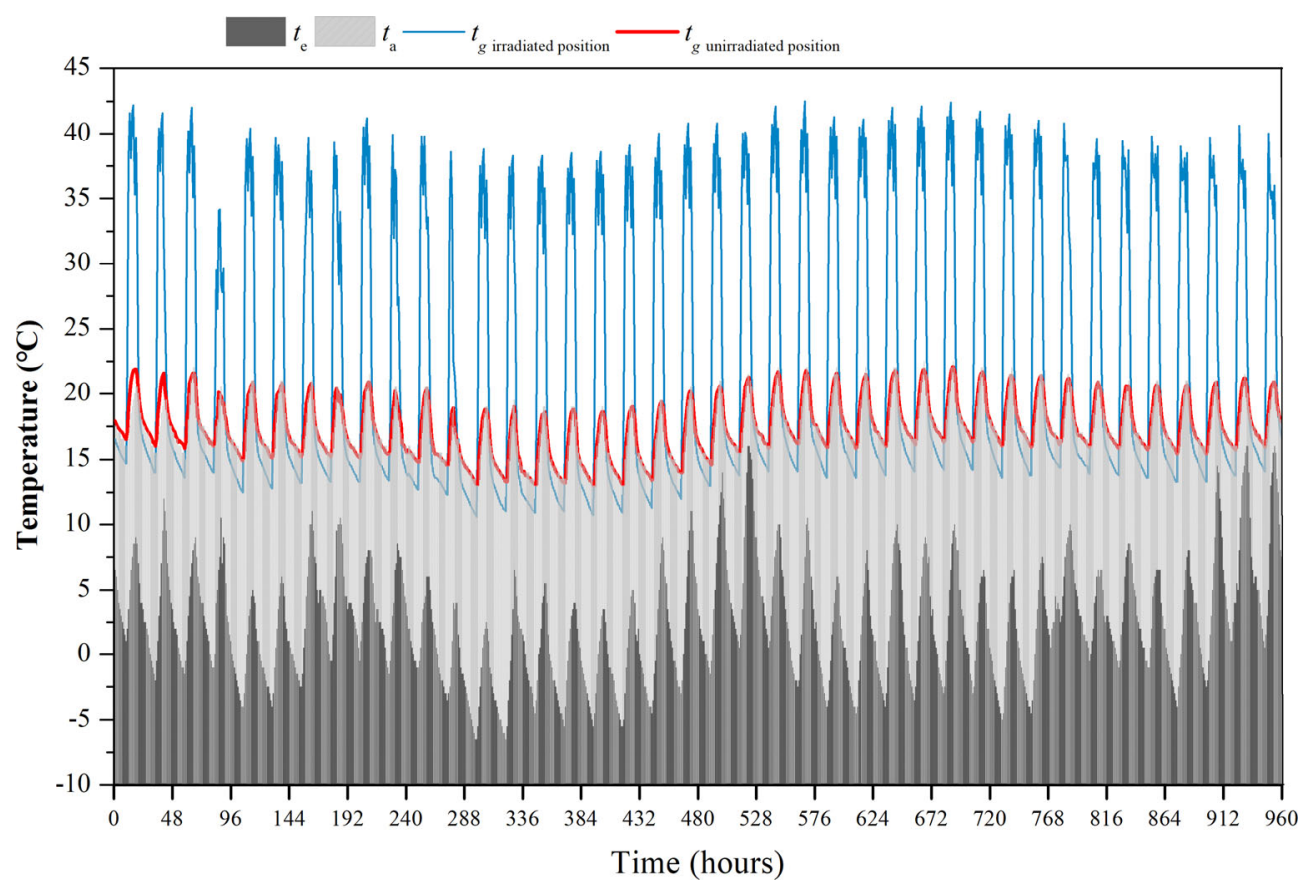

Fig. 9 Comparison of measured air temperature and black globe temperature 
represents the unirradiated position.

It can be seen that $t_{\mathrm{g}}$ at the unirradiated position shows a similar variation as the indoor air temperature (between 15 and $22^{\circ} \mathrm{C}$ ), with a standard deviation of $2.5^{\circ} \mathrm{C}$. Meanwhile, a considerable difference relative to the unirradiated position is observed for $t_{\mathrm{g}}$ at the irradiated position, which has a more significant variation from around 12 to over $40{ }^{\circ} \mathrm{C}$ and a higher standard deviation of $10.2^{\circ} \mathrm{C}$, implying $t_{\mathrm{g}}$ at the irradiated position has much higher dispersion.

Next, the index of $t_{\text {solarop }}$ was applied to indicate the condition of thermal comfort. Figure 10 depicts the variations in $t_{\text {solarop }}$ at positions along the center axis of the measured room. It can be observed that $t_{\text {solarop }}$ reaches 43.2 and $39.0^{\circ} \mathrm{C}$ at irradiated positions (P0 and P2), respectively, and then exhibits a remarkable decrease to $22.1{ }^{\circ} \mathrm{C}$ at unirradiated positions ( $\mathrm{P} 8$ and $\mathrm{P} 11$ ), corresponding to a reduction of around $20.0{ }^{\circ} \mathrm{C}$. The results reveal a significant difference between the $t_{\text {solarop }}$ at the irradiated and unirradiated positions that demonstrate the solar effect.

From Table 6, it can be noticed that in a southern room at the irradiated position, there is a distinct "overstepping" from the adaptive comfort criteria. $t_{\text {solarop }}$ is considerably higher than the upper band of the comfort range by up to $19.0^{\circ} \mathrm{C}$. In unirradiated areas, thermal condition tends towards the adaptive comfort for most of the daytime.

Overall, the results of the field measurements indicate that thermal discomfort of overheating occurs in sunlit areas for over two-thirds of the daytime (72.5\%) on winter days. In comparison, adaptive thermal comfort may be achieved in the unirradiated areas for most of the daytime (97.0\%). The overheating period is found to last for an average of 6 hours between 11:00 and 17:00, whereas the sensations of adaptive comfort correspond to the remainder of the time. In comparison, the condition of overcooling is rare in both irradiated and unirradiated positions, and the difference in $t_{\text {solarop }}$ is found to be over $20^{\circ} \mathrm{C}$ between the two positions. The difference in temperature provides evidence a notably non-uniform thermal environment is formed in the same space in the daytime due to the solar irradiance.

Generally, the indoor thermal environment in winter at high altitudes tend to be towards the cold side (Yang et al. 2013; Sun and Leng 2015; Gautam et al. 2019; Pokharel et al. 2020), or could be approached by the contribution of direct solar gain ( $\mathrm{Yu}$ et al. 2017). The discrepancies between the findings of this study and the previous studies lie in space type and thermal comfort incorporating solar effect. First, most previous studies focused on residential

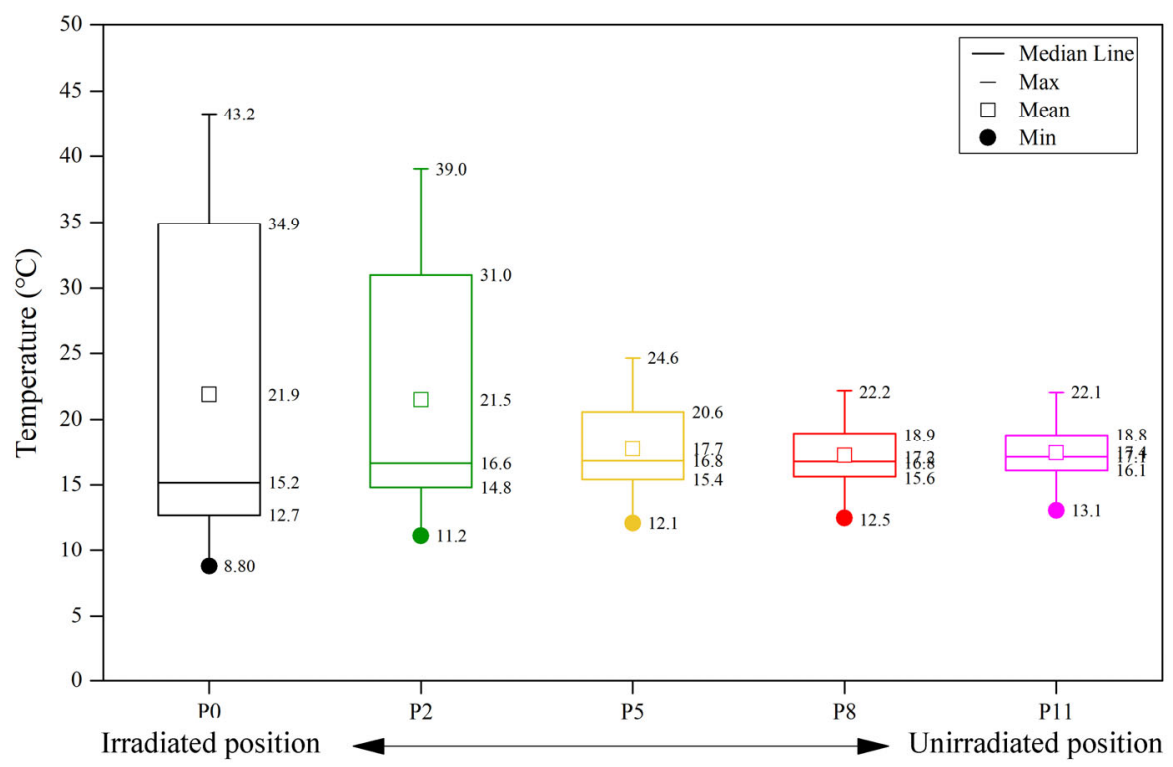

Fig. 10 Comparison of $t_{\text {solarop }}$ at different points during measurements

Table 6 Temporal distribution of $t_{\mathrm{op}}$ during daytime in the measurement

\begin{tabular}{ccc}
\hline & \multicolumn{2}{c}{ Position } \\
\cline { 2 - 3 } Comfort range & Irradiated (P2) & Unirradiated (P11) \\
\hline Overheating $t_{\mathrm{op}}>24.2^{\circ} \mathrm{C}$ & $72.5 \%$ & $0.0 \%$ \\
Comfort zone $13.6 \leq t_{\mathrm{op}} \leq 24.2^{\circ} \mathrm{C}$ & $24.5 \%$ & $97.0 \%$ \\
Overcooling $t_{\mathrm{op}}<13.6^{\circ} \mathrm{C}$ & $3.0 \%$ & $3.0 \%$ \\
\hline
\end{tabular}


space other than office space, in which there may have more constraints for occupants' adaption for thermal control (O'Brien et al. 2013; Halawa et al. 2014). Second, mostly the solar gain is considered as a contribution to an increase in indoor air temperature for high altitude, its impact on thermal comfort is not discussed. While for spaces like a unit-office type room, the position near the window with solar radiation is a primary area for occupants (Yao et al. 2016); thus, the direct solar effect is a critical factor in evaluating indoor thermal comfort in a climate with high-intensity solar radiation.

\subsubsection{Evaluation by simulation}

So far, we focused on thermal discomfort conditions via measurements of the thermal indoor environment; however, it is also necessary to evaluate the thermal conditions on an annual basis. Figure 11 depicts the annual variations of $t_{\text {solarop }}$ at typical positions of high irradiated and unirradiated
(P2 and P11) positions. The $t_{\text {solarop }}$ at irradiated position is found to exhibit a significant temporal difference between the winter and summer periods. During the winter period, from Nov through Feb, the $t_{\text {solarop }}$ at the irradiated position remains overheated $\left(24.2-40{ }^{\circ} \mathrm{C}\right)$ for $77.0 \%-92.3 \%$ of daytime, while it remains within the adaptive comfort range (16.9-29.7 ${ }^{\circ} \mathrm{C}$ ) during the summer daytime. Regarding unirradiated position, $t_{\text {solarop }}$ remains in the adaptive comfort range most of the daytime during winter, and temperature over $24.2{ }^{\circ} \mathrm{C}$ occurs for significantly less time. Meanwhile, the difference of $t_{\text {solarop }}$ between irradiated and unirradiated positions is considerably high by over $15^{\circ} \mathrm{C}$.

The spatial distribution of overheating in the test room model is further illustrated in Figure 12. The contour maps represent the percentage of daytime during which $t_{\text {solarop }}$ exceeds $24.2^{\circ} \mathrm{C}$ in winter and $29.7^{\circ} \mathrm{C}$ in summer. It can be observed that overheating by direct radiation occurs in the near-window area for a depth from 1 to 3 meters, and
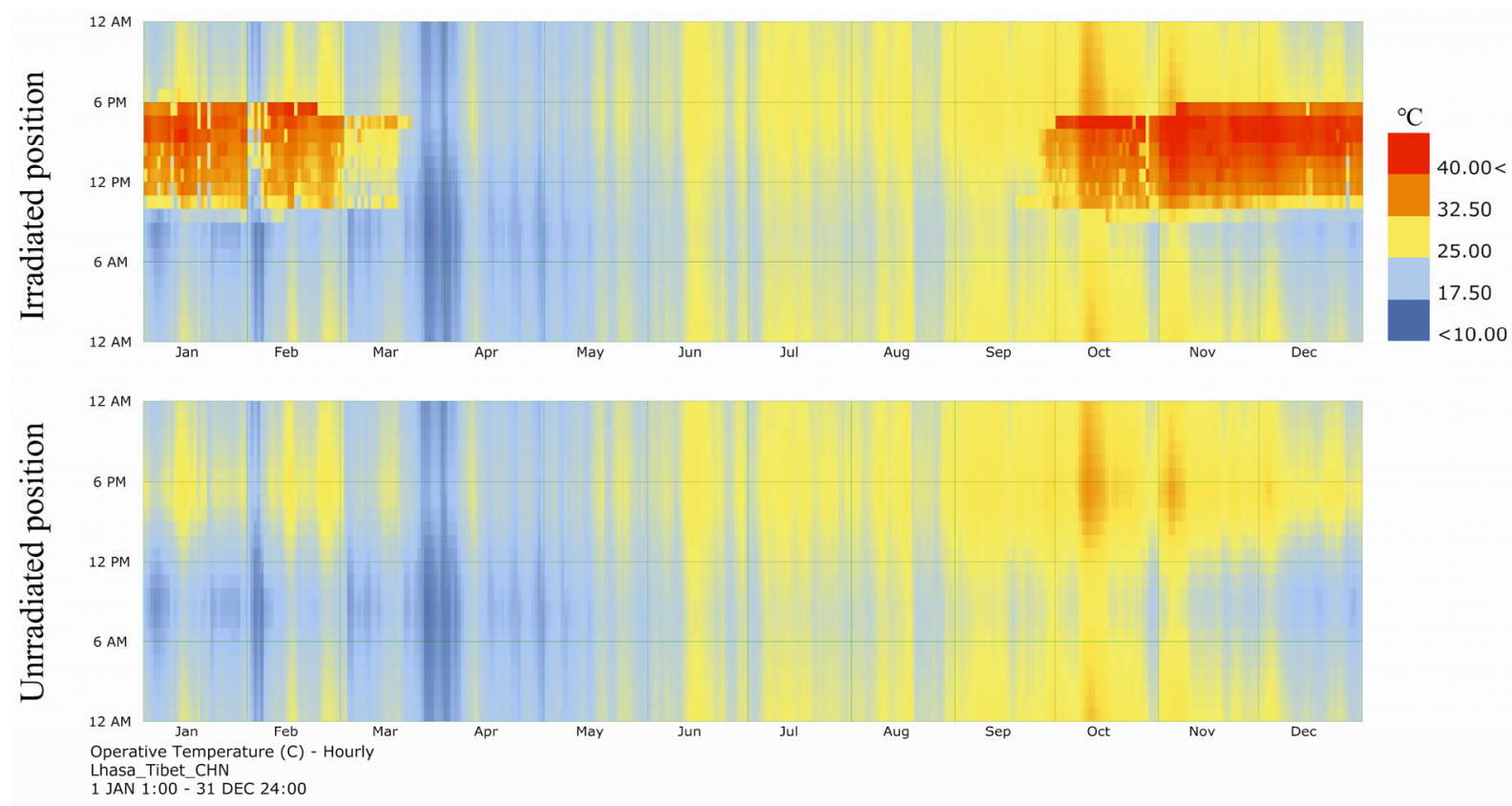

\begin{tabular}{|c|c|c|c|c|c|c|c|}
\hline \multirow{2}{*}{$\begin{array}{l}\text { Irradiated position } \\
\text { (P2) }\end{array}$} & \multicolumn{3}{|c|}{ Summer } & \multicolumn{4}{|c|}{ Winter } \\
\hline & Jun & Jul & Aug & Nov & Dec & Jan & $\mathrm{Feb}$ \\
\hline Overheating & $0.0 \%$ & $0.0 \%$ & $0.0 \%$ & $92.3 \%$ & $88.0 \%$ & $78.4 \%$ & $77.0 \%$ \\
\hline Adaptive comfort & $100 \%$ & $100 \%$ & $100 \%$ & $7.7 \%$ & $12.0 \%$ & $21.6 \%$ & $23.0 \%$ \\
\hline Overcooling & $0.0 \%$ & $0.0 \%$ & $0.0 \%$ & $0.0 \%$ & $0.0 \%$ & $0.0 \%$ & $0.0 \%$ \\
\hline Unirradiated position & \multicolumn{3}{|c|}{ Summer } & \multicolumn{4}{|c|}{ Winter } \\
\hline (P11) & Jun & Jul & Aug & Nov & Dec & Jan & Feb \\
\hline Overheating & $0.0 \%$ & $0.0 \%$ & $0.0 \%$ & $48.5 \%$ & $13.8 \%$ & $2.4 \%$ & $12.5 \%$ \\
\hline Adaptive comfort & $100 \%$ & $100 \%$ & $100 \%$ & $51.5 \%$ & $86.2 \%$ & $96.9 \%$ & $85.2 \%$ \\
\hline Overcooling & $0.0 \%$ & $0.0 \%$ & $0.0 \%$ & $0.0 \%$ & $0.0 \%$ & $0.7 \%$ & $2.3 \%$ \\
\hline
\end{tabular}

Fig. 11 Comparison of temporal distributions of $t_{\text {solarop }}$ at irradiated and unirradiated positions (only percentage of thermal condition during daytime in winter and summer is exhibited in the tables below) 

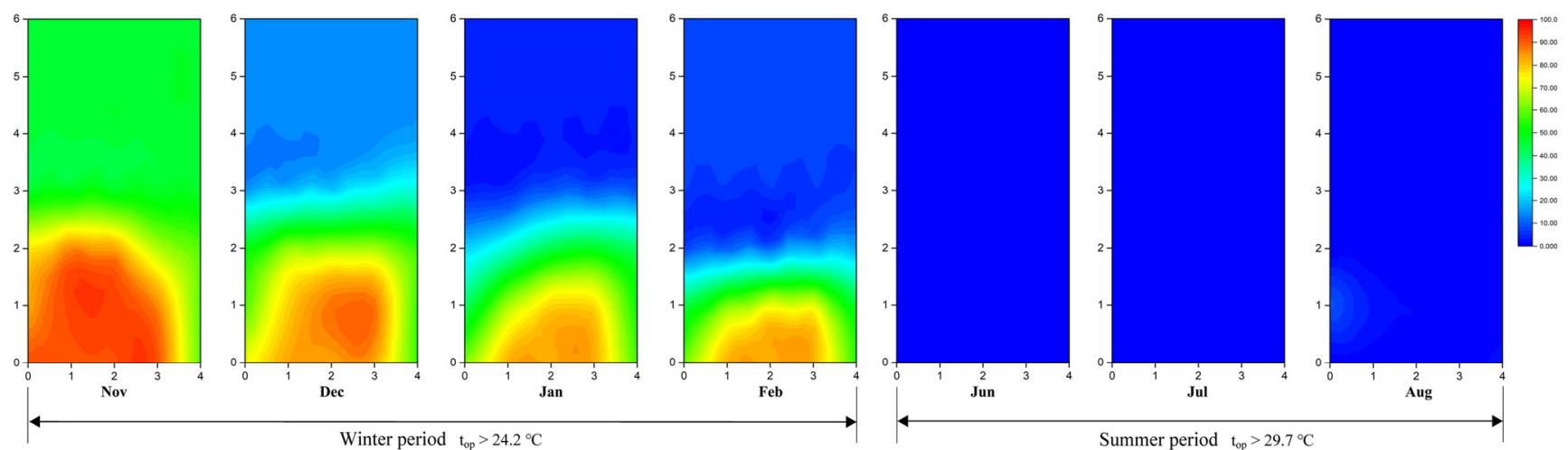

Fig. 12 Simulation of the temporal and spatial distributions of overheating (\%) during winter and summer periods

overheating in this area ranges from $50 \%$ to near $90 \%$ of the daytime during the winter period including Nov, Dec, Jan, and Feb. Moreover, overheating has the most impacts in Nov and Dec in terms of both spatial and temporal distribution. However, no overheating occurs during the summer.

The simulation results for annual evaluation suggest that in the irradiated areas, considerable overheating may occur during the winter period for the majority of daytime, while there is no occurrence of overheating during the summer. Normally passive solar gain is considered to improve thermal comfort in winter without risk of overheating, with the assumption that the indoor thermal environment is uniform. In addition, the indoor air temperature at the central point in space was generally used as the indicator for evaluation. While when the area near window is for primary use during daytime, solar radiation on the human body needs to be considered and solar-adjusted indicators are more necessary for the evaluation, otherwise the thermal problems due to the solar radiation and non-uniformity in winter might be ignored. The overheating in winter might cause more problems for two reasons. First, in a shared office, when two or more people occupy the same room, there will be conflicting thermal preference for the one in the irradiated area and the one in the unirradiated area (Halawa et al. 2014). Moreover, social factors may also impact the potential shade action to adjust thermal comfort (O'Brien et al. 2013). Second, in the simulation, no mechanical heating system is considered; however, the policy of urban heating being formulated for office buildings in Lhasa shortly can make overheating problems in winter more severe in the presence of mechanical heating. As radiant heat loss towards the glazing is not considered in the simulation, the simulated values of $t_{\text {opsolar }}$ might be higher than the actual situation, however the difference is considered very slight during daytime according to the comparison of simulated and measured data of MRT.

\subsection{Adaptive behaviors in response to solar radiation}

In terms of adaptive behavior, occupants were found to take certain forms of measures to achieve thermal comfort against solar radiation. In the form of methods to control thermal control, $83.3 \%$ responded by drawing curtains, $5.6 \%$ reported using hats or umbrellas near the window areas, and $1.4 \%$ reported opening the window. $38.9 \%$ reported moving to unirradiated or shaded areas after a period of stay in the sunlight. In comparison, 5.6\% reported changing their posture (such as turning their back to direct sunlight), and $2.8 \%$ reported changes in clothing style. Despite sunlit, more occupants prefer to stay in the near-window area. In response to overheating, some may choose to move away and stay in a shaded area for a period to restore thermal comfort and move back afterward. Other measures reported include drinking hot water, applying skincare products, and humidification. The results suggest that thermal discomfort due to the direct solar radiation is widely acknowledged, and adaptive behaviors to avoid sunlight are common among the occupants in southern-orientated offices, of which drawing curtain during working hours is the primary measure.

Occupants' behaviors were another important factor of thermal comfort (Jin et al. 2019). Compared with general adaptive behaviors, in response to the discomfort of overheating in winter adoptions are different and more limited.

(1) Clothing change was found to be seldom adopted in response to overheating in our survey. Although, it is generally adopted in response to both cold and heat. The reason could be that in urban areas, contemporary clothing has been the dominant clothing style and is not applicable for partially wearing as traditional Tibetan robes in response to thermal discomfort by solar radiation.

(2) Change of posture in the studied condition, is turning the back to sunlight, to shade the facial part and increase the area for solar gain on the back. And this behavior 
responds to directional radiant source other than convective heat transfer by adopting an open posture to increase the surface area for heat loss or cuddling up to reduce the area for heat loss.

(3) Movement between different thermal environments is an approach adopted. This behavior was also found to be often adopted in residential spaces in Lhasa (Yu et al. 2017), while there could be a difference in between. In residential spaces, occupants more often move around (such as for housework). In contrast, in an office occupants usually stay in a fixed position at their desks with less flexibility for movement. This behavior might be adopted instead of shading due to the social constraints in a shared room (O'Brien et al. 2013). Further, occupants remain in a state of physical inactivity for longer periods, and the duration of inactivity is a key factor in overheating (Nicol et al. 2010). Therefore, the overheating problem is of more prominence in office rooms compared to residential spaces.

(4) Although opening a window is another general adaptive approach in response to heat (Humphreys and Nicol 1998). This approach is seldom adopted in the studied condition with winter overheating because introducing the ambient low-temperature air by opening the window is a costly way to alleviate discomfort (Bessoudo et al. 2010) and reduce adaptive thermal comfort in the unirradiated position.

(5) Indoor solar shading is found to be a primary behavioral action for thermal control in the studied condition. Drawing curtains is mostly adopted to provide shade from sunlight in modern office rooms, which agrees with the previous study that in the absence of air conditioning, occupants are more inclined to use shades for the prevention of excessive solar heat (O'Brien et al. 2013). Moreover, hats and umbrellas were also reported to be adopted occasionally. However, this approach is against the principle of passive solar utilization in terms of energy efficiency; moreover, it may reduce indoor air temperature and destruct the adaptive thermal comfort based on the contribution of solar heat to indoor air temperature. Therefore, a proper winter shading device is a necessary approach to meet the needs of both shading and passive solar use.

\subsection{Impact of solar adjustment by drawing curtains on} energy performance

Room heating is usually required when the curtains are drawn to block direct solar gain. Table 7 compares the energy performance between shaded and unshaded conditions during winter. It was found that the heating load of the model (B) is considerably higher than that of the model (A)
Table 7 Comparison of energy performances of Models (A) and (B)

\begin{tabular}{cccccc}
\hline & & $\begin{array}{c}\text { Heating } \\
\text { load } \\
\left(\mathrm{kWh} / \mathrm{m}^{2}\right)\end{array}$ & $\begin{array}{c}\text { Solar gain } \\
\left(\mathrm{kWh} / \mathrm{m}^{2}\right)\end{array}$ & $\begin{array}{c}\text { Electric } \\
\text { lighting } \\
\left(\mathrm{kWh} / \mathrm{m}^{2}\right)\end{array}$ & $\begin{array}{c}\text { Conduction } \\
(\text { glazing }) \\
\left(\mathrm{kWh} / \mathrm{m}^{2}\right)\end{array}$ \\
\hline $\begin{array}{c}\text { Model } \\
(\mathrm{A})\end{array}$ & Unshaded & 26.6 & 125.1 & 4.1 & -70.5 \\
$\begin{array}{c}\text { Model } \\
(\mathrm{B})\end{array}$ & $\begin{array}{c}\text { Shaded } \\
\text { (curtain) }\end{array}$ & 49.7 & 43.9 & 11.0 & -22.3 \\
\hline
\end{tabular}

(49.7 against $26.6 \mathrm{kWh} / \mathrm{m}^{2}$ ), which indicates that drawing curtains may correspond to an increased energy requirement of approximately 1.9 times that of the no-shade condition. In terms of heat balance, the model (A) affords nearly thrice the solar heat gain obtained with the model (B) (125.1 against $43.9 \mathrm{kWh} / \mathrm{m}^{2}$ ) and three times the heat loss relative to that for the model (B) via the exterior glazing. Meanwhile, the lighting load is significantly higher for the model (B). These results suggest that the generally adopted strategy of shading by use of curtains reduces solar passive heat gain by $64.9 \%$ and increases both the heating and lighting loads. In contrast, it reduces heat loss by conduction through the exterior glazing. In total, the heating load increases when a shading strategy based on blocking of direct solar gain is adopted, and the utilization of passive solar gain by current local design standards might be significantly overestimated.

The present requirement of WWR in Tibetan building codes regarding energy efficiency generally focuses on the balance between solar heat gain and heat loss through glazing, while the results imply that the required WWR may not achieve expected energy saving due to the occupants' solar adjustment, and the control of WWR needs to be considered with the concern of the overheating caused by solar radiation in winter.

\subsection{Approach and performance of winter solar shading}

\subsubsection{Design description}

The passive, adaptive, and free-running building is helpful to maintain comfortable heating and conceived as an action in response to heat (Nicol et al. 2010). In a previous study for passive solar design, an alternative to general solid Trombe wall was proposed that uses vertical mass louvers to store heat from the afternoon in the masonry while allowing solar heat and sunlight into the building in the morning for quickly heating the building (Total Envrionment Action Inc 1980). The solar louvers in this system have both functions of shading and thermal storage, which block direct solar irradiance and transfer solar heat to indoor surfaces, thereby alleviating the sharp contrast in temporal and spatial temperature distributions.

A configuration of thermal mass shading (TMS) with 
solar louver is developed based on the concept of alternative Trombe wall, and its performance as a winter shading device is examined (Figure 13). The geometry of the solar louvers is defined as $200 \mathrm{~mm}$ thick, $800 \mathrm{~mm}$ long, and $2800 \mathrm{~mm}$ high. The louvers are placed at $45^{\circ}$ towards south-west for shading and to collect solar radiation and heat. Further, solar louvers are assumed to be placed at a distance of $20 \mathrm{~cm}$ from the exterior glazing. The material used for the mass is black cast concrete (dense). The performance of the proposed TMS device is examined using simulations in DesignBuilder (version 4.2). The room model, gird, and boundary condition for the simulation are the same as described in Section 2.1. The space between the exterior glazing and TMS is set as a zone type cavity by a virtual partition, and southern WWR is $100 \%$ as full glazing is provided to maximize the direct solar gain.

\subsubsection{Performance of the TMS}

To evaluate the performance of the TMS of solar louver on the indoor thermal environment, the temporal distribution of overheating, thermal comfort, and overcooling at typical irradiated and unirradiated positions were compared with the base case of the room module previously used for prediction. As displayed in Figure 14, it can be observed that at a normal irradiated position (P2), time of overheating during winter was significantly reduced by $68.9 \%, 62.2 \%$, $59.2 \%$, and $58.6 \%$ in Nov, Dec, Jan, and Feb respectively, and the time of comfort zone yielded a corresponding increase. Also, no time of overcooling was observed in both cases. Regarding the unirradiated position, overheating time in winter was almost diminished in the case of the solar louver, and an increase in time of thermal comfort can be observed. Moreover, no overcooling occurs during winter. Meanwhile, no overheating or overcooling was observed for the summer period for both cases. The average maximum $t_{\text {solarop }}$ of the TMS case at irradiated position (P2) was $5.4^{\circ} \mathrm{C}$ lower than that of the base case during winter, while the average minimum $t_{\text {solarop }}$ was higher by $0.15^{\circ} \mathrm{C}$. In terms of energy balance, the heating contribution of solar louvers is $28.5 \mathrm{kWh} / \mathrm{m}^{2}$ for winter, and $3.2 \mathrm{kWh} / \mathrm{m}^{2}$ for summer.

The above results suggest that the TMS device shows improved performance in the indoor thermal environment compared with the direct-gain system by large southern glazing. The TMS device is efficient in regulating indoor thermal environments by reducing the time of overheating and increasing that of comfort.

In comparison, most previous studies have suggested the use of sizeable south-facing glazing to increase the amount of direct solar heat, for high altitude places such as Lhasa ( Feng et al. 2013; Sun and Leng 2015). Furthermore, it is suggested that the southern WWR in Lhasa should be between $50 \%$ and $70 \%$ (Feng et al. 2013). In a previous systematic study of passive solar heating technology for cold climate in China, a combination of Trombe wall and direct-gain window is recommended as optimal design for Lhasa with WWR of $50 \%$ and direct-gain window and attached sunspaces are considered as alternatives (Liu et al. 2018). Moreover, present bioclimatic analysis (e.g., Bioclimatic charts or Climate consultant) generally does not suggest the strategy of solar shading for winter in cold climates.

The proposed and previous strategies both agree with large glazing for passive solar heat gain, while the primary

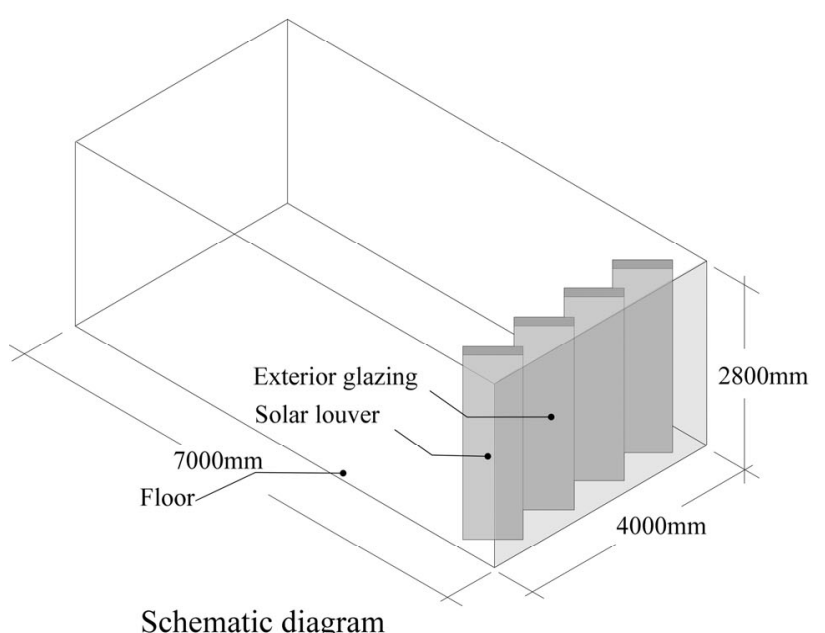

Schematic diagram

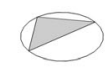

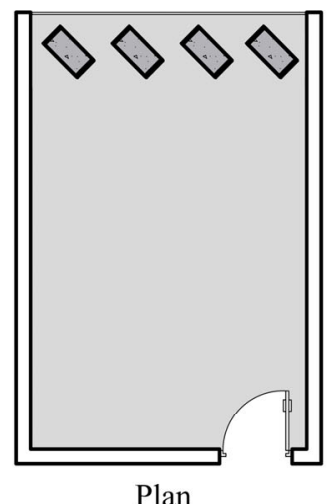

Plan

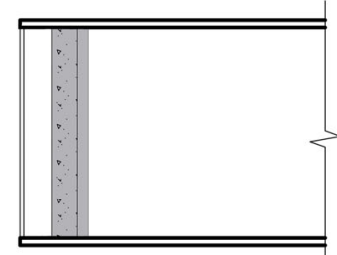

Section

Fig. 13 The configuration of the proposed TMS device 

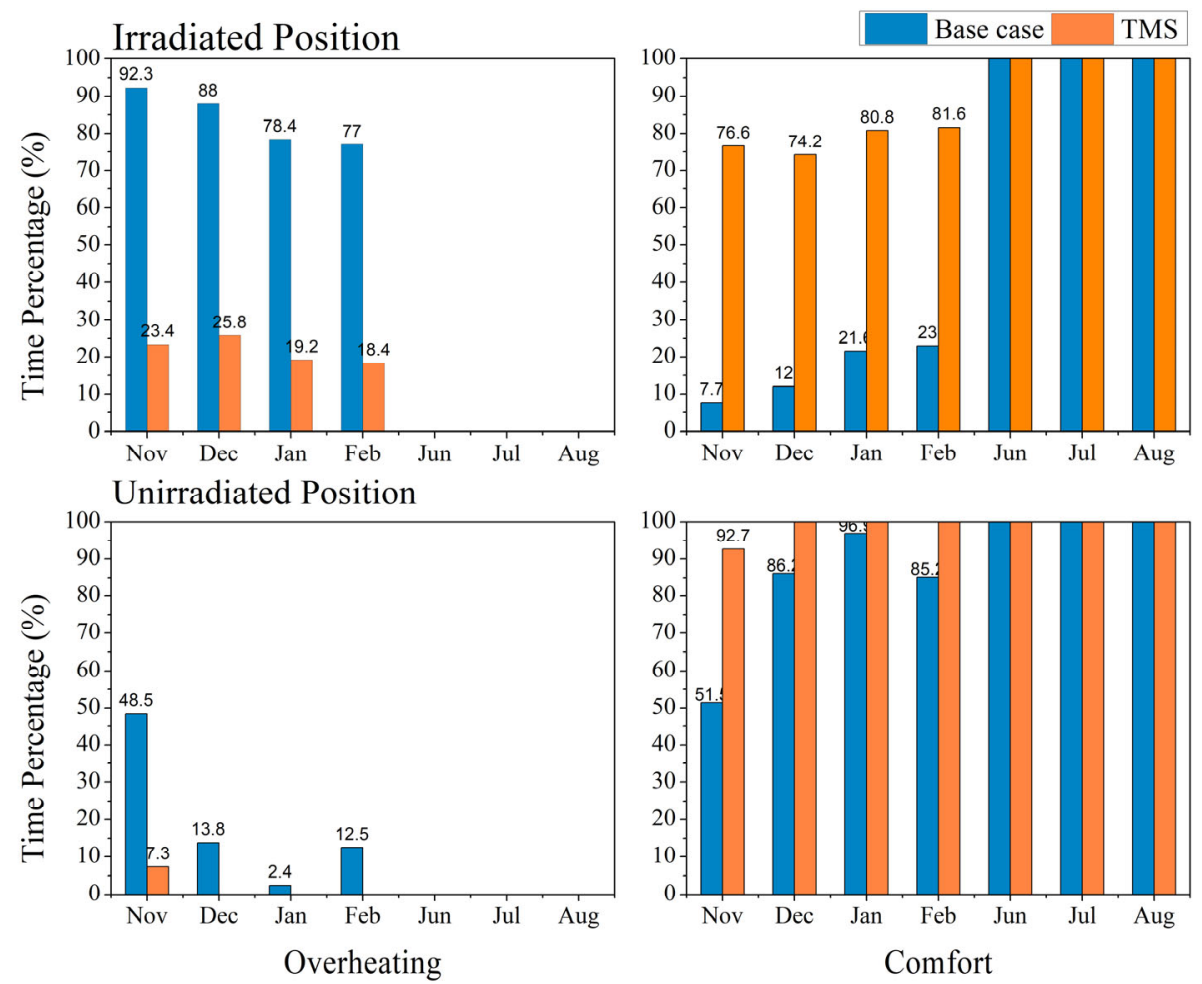

Fig. 14 Comparisons of spatial distribution of $t_{\text {solarop }}$ between the base case and TMS case

difference lies in the usage mode of solar radiation. Other measures, such as change in SHGC and WWR, may also improve the thermal environment in response to solar radiation, however, with limitations for this specific situation. Upgrading of glazing type for variation of SHGC such as autonomous responsive dimming glass can meet the requirements for shading and natural lighting and is suitable for cooling in summer (Inoue 2003), while it has a limitation in the utilization of passive solar gain in winter. Similarly, the variation of WWR may also have such limits for passive solar use. Moreover, the conventional solar shading strategies to reduce solar heat gain by blocking solar irradiance are neither appropriate design options.

The developed TMS of the solar louver is an attempt to meet the purpose of both shading and passive solar gain and showed notable improvement in the indoor thermal environment. However, despite the effectiveness of the prototype of TMS, negative impacts on view, structure load, and natural lighting may also exist. Thus, the optimization of solar louvers angles and other forms of TMS shading still need to be further explored. Nevertheless, our study provides an exploration of winter solar shading as an extension of both passive solar design and solar shading.

\section{Conclusion}

In this study, thermal discomfort of overheating caused by solar irradiance in winter was evaluated in the case of Lhasa via field measurements and simulation studies, occupants' adaptive behaviors in response to overheating was investigated. Moreover, a conceptual winter solar shading design was developed.

(1) The field measurements indicate the occurrence of overheating in winter in the near-window space where most occupants prefer as the working space. At an irradiated position, $t_{\text {solarop }}$ is considerably higher than the upper band of the comfort range for the majority of the daytime. Evaluation by simulation on the annual base further revealed that in terms of temporal variation, the overheating period annually spans the whole winter period from Nov through Feb. On the contrary, very little overheating occurs during the summer period.

(2) Occupants adopted various adaptive behaviors to restore thermal comfort in the presence of solar heat, most of which are related to solar shading. Moreover, drawing curtains is identified as the major thermal control.

(3) The energy simulation reveals that occupant solar adjustment of drawing curtains may lead to increased heating loads by 1.9 times in a room model with the WWR requirements as per the local design standard, and the efficiency of currently passive solar heat might be overestimated by a factor of three.

(4) The TMS device with solar louvers proved to be an effective approach for the improvement of the thermal 
environment in winter. The developed TMS device is estimated to yield a notable reduction in time of overheating by $62.2 \%$ on average, and a corresponding increase in time of comfort.

There are some limitations of this study and need to be further explored in future work, including a detailed questionnaire survey for subjective evaluation of thermal comfort in a non-uniform environment considering direct solar radiation, and the impact of thermal mass shading on integrated performance of shading and passive solar use.

\section{Acknowledgements}

This work was supported by the National Natural Science Foundation of China (No. 51278525) and the grant of the Top Youth Programme of Wuhan University.

Open Access: This article is licensed under a Creative Commons Attribution 4.0 International License, which permits use, sharing, adaptation, distribution and reproduction in any medium or format, as long as you give appropriate credit to the original author(s) and the source, provide a link to the Creative Commons licence, and indicate if changes were made.

The images or other third party material in this article are included in the article's Creative Commons licence, unless indicated otherwise in a credit line to the material. If material is not included in the article's Creative Commons licence and your intended use is not permitted by statutory regulation or exceeds the permitted use, you will need to obtain permission directly from the copyright holder.

To view a copy of this licence, visit http:// creativecommons.org/licenses/by/4.0/

\section{References}

Arens E, Hoyt T, Zhou X, et al. (2015). Modeling the comfort effects of short-wave solar radiation indoors. Building and Environment, 88: 3-9.

Arens E, Heinzerling D, Paliaga PE (2018). Sunlight and indoor thermal comfort. ASHRAE Journal, 2018(7): 12-21.

ASHRAE (2002). Guideline 14-2014-Measurement of Energy, Demand, and Water Savings. Atlanta: American Society of Heating, Refrigeration and Air-Conditioning Engineers.

ASHRAE (2009). ASHRAE Handbook Fundamentals. Atlanta: American Society of Heating, Refrigeration and Air-Conditioning Engineers.

ASHRAE (2017). ASHRAE-55. Thermal Environmental Conditions for Human Occupancy. Atlanta: American Society of Heating, Refrigeration and Air-Conditioning Engineers.

Bessoudo M, Tzempelikos A, Athienitis AK, et al. (2010). Indoor thermal environmental conditions near glazed facades with shading devices-Part I: Experiments and building thermal model. Building and Environment, 45: 2506-2516.
Blumthaler M (2012). Solar radiation of the high Alps. In: Lütz C (ed), Plants in Alpine Regions. Vienna: Springer.

Blumthaler M, Ambach W, Ellinger R (1997). Increase in solar UV radiation with altitude. Journal of Photochemistry and Photobiology B: Biology, 39: 130-134.

Bodach S, Lang W, Hamhaber J (2014). Climate responsive building design strategies of vernacular architecture in Nepal. Energy and Buildings, 81: 227-242.

Cappelletti F, Prada A, Romagnoni P, et al. (2014). Passive performance of glazed components in heating and cooling of an open-space office under controlled indoor thermal comfort. Building and Environment, 72: 131-144.

Chaiyapinunt S, Khamporn N (2020). Effect of solar radiation on human thermal comfort in a tropical climate. Indoor and Built Environment, https://doi.org/10.1177/1420326X19891761

Chaiyapinunt S, Phueakphongsuriya B, Mongkornsaksit K, et al. (2005). Performance rating of glass windows and glass windows with films in aspect of thermal comfort and heat transmission. Energy and Buildings, 37: 725-738.

DB54/0015-2007 (2007). Tibetan Local Standard of Heating Design for Civil Buildings. Department of Housing and Urban Rural Development of Tibet Autonomous Region, Lhasa. (in Chinese)

DB540001-2016 (2016). Design Standard for Energy Efficiency of Civil Builings in Tibet. Department of Housing and Urban Rural Development of Tibet Autonomous Region, Lhasa. (in Chinese)

De Dear RJ, Brager G (1998). Towards an adaptive model of thermal comfort and preference. ASHRAE Transactions 104(1):145-167.

Feng Y, Yang X, Zhong h (2013). Heating potential of passive solar building in Lhasa. Jounral of $H V \mho A C, 43(6)$ : 31-34.(in Chinese)

Gautam B, Rijal HB, Shukuya M, et al. (2019). A field investigation on the wintry thermal comfort and clothing adjustment of residents in traditional Nepalese houses. Journal of Building Engineering, 26: 100886.

Halawa E, van Hoof J, Soebarto V (2014). The impacts of the thermal radiation field on thermal comfort, energy consumption and control-A critical overview. Renewable and Sustainable Energy Reviews, 37: 907-918.

Humphreys MA, Nicol JF (1998). Understanding the adaptive approach to thermal comfort. ASHRAE Transactions 104(1): 991-1004.

Inoue $\mathrm{T}$ (2003). Solar shading and daylighting by means of autonomous responsive dimming glass: practical application. Energy and Buildings, 35: 463-471.

ISO 7726:1998 (1998). Ergonomics of the Thermal EnvironmentInstruments for Measuring Physical Quantities Ergonomie. Geneva: International Standardization Organization.

Jin H, Liu S, Kang J (2019). Thermal comfort range and influence factor of urban pedestrian streets in severe cold regions. Energy and Buildings, 198: 197-206.

Khamporn N, Chaiyapinunt S (2014). An investigation on the human thermal comfort from a glass window. Engineering Journal, 18: 25-44.

Kottek M, Grieser J, Beck C, et al. (2006). World map of the KöppenGeiger climate classification updated. Meteorologische Zeitschrift, 15: 259-263. 
Lee ES, Selkowitz SE (1995). The design and evaluation of integrated envelope and lighting control strategies for commercial buildings. Paper presented at ASHRAE Winter Meeting.

Liu Y, Jiang J, Wang D, Liu J (2018). The passive solar heating technologies in rural school buildings in cold climates in China. Journal of Building Physics, 41: 339-359.

Marino C, Nucara A, Pietrafesa M (2015). Mapping of the indoor comfort conditions considering the effect of solar radiation. Solar Energy, 113: 63-77.

Marino C, Nucara A, Pietrafesa M (2017a). Thermal comfort in indoor environment: Effect of the solar radiation on the radiant temperature asymmetry. Solar Energy, 144: 295-309.

Marino C, Nucara A, Pietrafesa M, et al. (2017b). The effect of the short wave radiation and its reflected components on the mean radiant temperature: modelling and preliminary experimental results. Journal of Building Engineering, 9: 42-51.

Milne M (2016). Climate Consultant v6.0. Available at http:// www.energy-design-tools.aud.ucla.edu/

Newsham GR (1994). Manual control of window blinds and electric lighting: implications for comfort and energy consumption. Indoor and Built Environment, 3: 135-144.

Nicol F, Humphreys M, Roaf S (2010). Adaptive Thermal Comfort: Principles and Practice. London: Routledge.

Nie Q, Zhao S, Zhang Q, et al. (2019). An investigation on the climateresponsive design strategies of vernacular dwellings in Khams. Building and Environment, 161: 106248.

O’Brien W, Kapsis K, Athienitis AK (2013). Manually-operated window shade patterns in office buildings: a critical review. Building and Environment, 60: 319-338.
Pokharel TR, Rijal HB, Shukuya M (2020). A field investigation on indoor thermal environment and its associated energy use in three climatic regions in Nepal. Energy and Buildings, 222: 110073.

Singh MC, Garg SN, Jha R (2008). Different glazing systems and their impact on human thermal comfort-Indian scenario. Building and Environment, 43: 1596-1602.

Sun H, Leng M (2015). Analysis on building energy performance of Tibetan traditional dwelling in cold rural area of Gannan. Energy and Buildings, 96: 251-260.

Total Envrionment Action Inc (1980). Passive Solar Design Handbook. Washington, DC: US Department of Energy.

Wang Z (2004). Selection of themal comfort indexes in the field study. Journal of HV\&AC, 34(12): 39-42. (in Chinese)

Yang L, Yan H, Xu Y, et al. (2013). Residential thermal environment in cold climates at high altitudes and building energy use implications. Energy and Buildings, 62: 139-145.

Yao J, Chow DHC, Zheng R, et al. (2016). Occupants' impact on indoor thermal comfort: A co-simulation study on stochastic control of solar shades. Journal of Building Performance Simulation, 9: 272-287.

Yu W, Li B, Yao R, et al. (2017). A study of thermal comfort in residential buildings on the Tibetan Plateau, China. Building and Environment, 119: 71-86

Zomorodian ZS, Tahsildoost M (2017). Assessment of window performance in classrooms by long term spatial comfort metrics. Energy and Buildings, 134: 80-93. 